\title{
OPEN Catalytic liquefaction of sewage sludge to small molecular weight chemicals
}

\author{
Yuehu Wang ${ }^{1,2 \bowtie}$, Feihong Tian ${ }^{1,2}$, Peimei Guo ${ }^{1,2}$, Dazhen $\mathrm{Fu}^{1,2}$, Hero Jan Heeres ${ }^{3}$, \\ Taotao Tang ${ }^{1,2}$, Huayu Yuan ${ }^{1,2}$, Bing Wang ${ }^{1,2}$ \& Jiang $\mathrm{Li}^{1,2}$
}

The catalytic hydrotreatment of sewage sludge, the wet solid byproducts from wastewater treatment plants, using supported Ir, Pt, Pd, Ru catalysts had been investigated with different solvent conditions. Reactions were carried out in a batch set-up at elevated temperatures $\left(400^{\circ} \mathrm{C}\right)$ using a hydrogen donor (formic acid (FA) in isopropanol (IPA) or hydrogen gas), with sewage sludge obtained from different sampling places. Sewage sludge conversions of up to $83.72 \%$ were achieved using $\mathrm{Pt} / \mathrm{C}$, whereas the performance for the others catalysts is different and solvent had a strong effect on the conversion rate and product constitution. The sewage sludge oils were characterised using a range of analytical techniques (GC, GC-MS, GCxGC, GPC) and were shown to consist of monomers, mainly alkanes and higher oligomers.

Sewage sludge includes dewatered sewage of wastewater treatment plant, digging sludge of city sewer and sum wadi dirt mud ${ }^{1}$. Dewatered sewage from sewage process factory is the main source. Dewatered sewage of sewage process factory is the half solid or solid material in sewage process course, and uninclude slag, scum, and grit. Usually quantity of dewatered sewage increases with the increace of sewage output amount and process quantity due to the acceleration of urbanization. For example, in china, by september 2016, there were 3976 sewage process factories, and capacity of sewage process is about 170 million $\mathrm{m}^{3} /$ day. Amount of wet dewatered sludge of $80 \%$ moisture content reached to 45,900 thousand ton per year if the produce rate of dewatered sludge refer to 1.5 ton sewage sludge per ten thousand ton waste water ${ }^{2}$. Dewatered sewage sludge will attain to 60,000-90,000 thousand ton to 2020 depend on the forecast of correlated nation department of china ${ }^{3}$. The harmless treatment disposal rate of dewatered sewage sludge is only $33 \%$ and $67 \%$ was disposed without harmless treatment disposal. Random stack of dewatered sewage sludge has led to serious environment pollution and bring to a series of economy and society problems.

On the one hand, sewage sludge is the heterogeneous mixture what was proceed and aggregated in all sedimentation tank, which is composed of organic relic, microorganism causative agent, parasite egg, inorganic granule, and colloid. It is putrescibility and metamorphism, and then foul maleficence gas will be distributed if it is not processed in time and cause to severe environment pollution, and bring sever health menace to human. Its main characteristic is moisture content is very high $(95 \%-99 \%)$, dewater of it is difficult and its volume is usually huge, which make its process and handle is difficult and transport expense is considerable. On the other hand, dewatered sewage sludge not only include abundant organic carbon source, moreover it also contains mass heavy metal as well as abundant nitrogen, phosphorus and kalium, so it could be recycled as a sort of resource. Vinay Kumar Tyagi and others suggested dewatered sewage sludge could be used as a reproducible resource of energy and organic chemical as early as $2013^{4}$.

In fact, dewatered sewage sludge or sewage process factory is an important transfer station in the material cycle of human life. A new abundant, sustainable, and reproducible source resource of energy and chemical could be provided for human if its upstream and downstream cycle path is penetrated (Fig. 1).

Based on the analysis of Fig. 1, we can see that the resource technology for dewatered dewage sludge is a complicated and multi-scale science problem. It needs consider both of water treatment effect in the upstream and a series of target optimizing foundation in the downstream for the resource of dewatered sewage sludge. multi-scale associated research and tackle key problem is a sort of effective method for the similar complicated science problem to actualize technology and industrialization span development, consulting the successful

${ }^{1}$ College of Resources and Environmental Engineering, Guizhou University, Guiyang 550025, China. ${ }^{2}$ Observation and Research Station for Guizhou Karst Environmental Ecosystems, Guiyang 550025, China. ${ }^{3}$ Chemical Engineering Department, ENTEG, University of Groningen, Nijenborg 4, 9747 AG Groningen, The Netherlands. ${ }^{\square}$ email: wangyuehu814081@163.com 


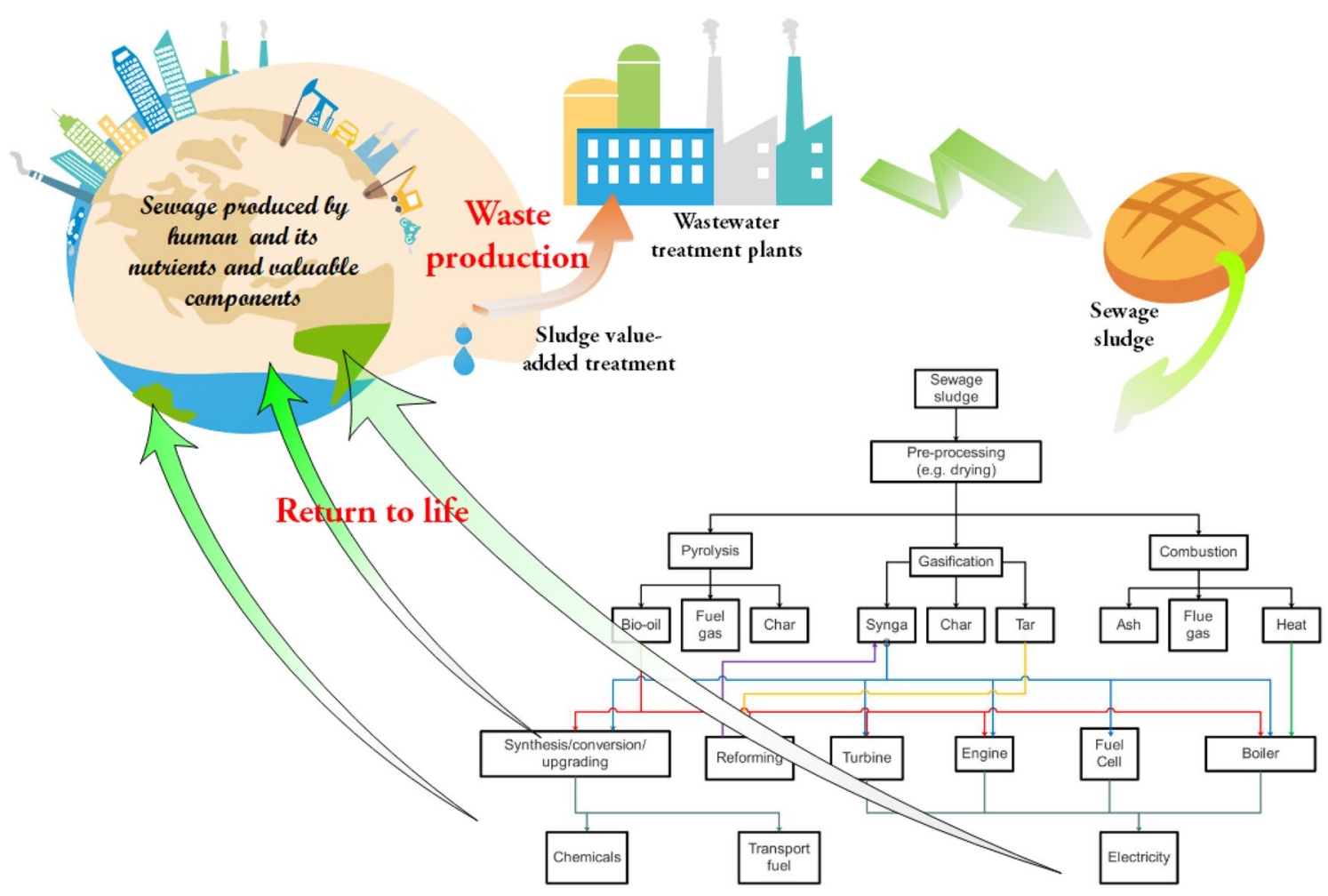

Figure 1. Role of sewage sludge in the water cycle of material circulation in human life ${ }^{4}$.

industrialization history of coal liquefication in China. Scale effect is crucial in complicacy problem and substance diversity research. Difference scale often causes the difference of mutual force and then result in qualitative difference of substance performance and its movement law and principle. Kui Wang figured out that any substance movement in complicacy system must involve in substance structural change, while structural change is a multi-level variation from primary structure to advanced structure. Chemistry of levels above molecule is a part of complicacy system chemistry investigate, because complicacy system research must be multi-level. Research of levels above molecule and the followed research of complicacy system may bring chemistry into a new realm ${ }^{5}$. Siliang Zhang reputed that space-time multi-scale characteristic is a common characteristic of all complicacy phenomenal in process engineering. It is quite difficult to find the relation between different scale in the substance transformation research if some different scale of substance phenomenal is chosen as target due to the difficulty of microcosmic and macroscopical data statistical treatment. However, It is probability to acquire essential knowing from appearance and process research or control will be qualitatively changed if such difficults are conquered ${ }^{6}$.

Multi-scale problem acted an important role in the development of modern science. nowadays, it gains comprehensive attention and application in the energy and resource research of biomass. It comes down to different scale of heat transfer ${ }^{7,8}$, compound material and analysis of biomass construction at different scale ${ }^{9-16}$, different scale of thermodynamics and dynamics for biomass treatment process ${ }^{6,15-25}$, different scale of chemistry mechanism ${ }^{26-32}$ and multi-scale coupling in biomass treatment ${ }^{32-45}$. Mushrif figured that multi-scale tool is a effective means in biomass transform technology ${ }^{46}$, Coupling of multi-scale is more important in the research of energy and resource for biomass ${ }^{47-59}$. but research papers with multi-scale coupling tool in the research of resource of dewatered sewage sludge is still rare. He and Zhang studied the multi-scale construction analysis of hydrothermal coke which was maken from dewatered dewage sludge $e^{60,61}$, and which is pioneering in the research of resource of dewatered dewage sludge with multi-scale analysis tool. balance between forepart water treatment and followed dewatered dewage sludge is used as a resource of organic biomass in the carbon sink of earth is very important because it is a key step. therefore, resource of dewatered sewage sludge is a multi-scale and multi-levels science problem, and application of analysis tools of multi-scale to the whole process maybe promote the research develops to a new level. Musun Guo figured out that cosmic substance construction there are 5 big levels, namely below atom level, molecule and its gather state level, biologic level, telluric level and $\operatorname{cosmic~level~}^{62}$. we showed the referred multi-scale problems in the process of catalytic crack of dewatered sewage sludge into small chemicals since its generation followed Guo's analysis and generalization for multi-scale problem in his book named $<$ multi-scale effect in the process of substance transform $>^{62}$.

Based on this analysis, we found that resource of dewatered dewage sludge is involved in all levels except of the universe level (Fig. 2). research for the coupling and correlation of biologic level and molecule and its gather state level should be the core problem in the complicacy multi-scale problem of the resource of dewatered dewage sludge. Research for this problem not only need to satisfice the technical demand for the forepart water treatment, it also affects the product of the back-end resource of dewatered dewage sludge, for example, the selectivity for 


\section{Analysis of multi-scale problems involved in sludge recycling}

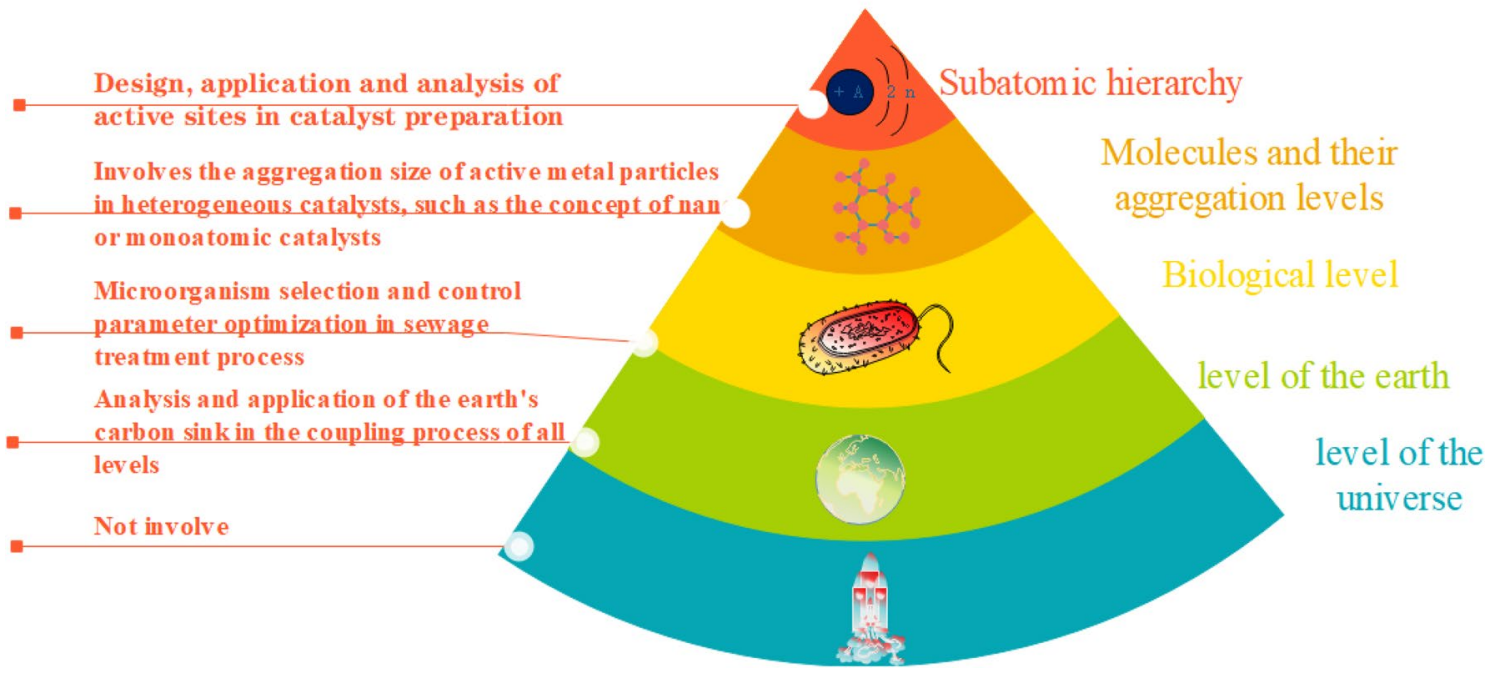

Figure 2. Analysis of multi-scale problems involved in sludge recycling.

certain valuable chemicals. In the technology route of chemical manufacture, thermochemistry treatment of dewatered dewage sludge is a sort of effective technology path, it is a representation of multi-scale problem for resource of dewatered dewage sludge at the level of molecule and its gather state level.

According to the participation degree of oxygen in the chemistry reaction, Wang Yi summarized that there are three technologies, included in pyrolysis, gasification and combustion after advanced process of dewatered dewage sludge such as dryness and so $\mathrm{on}^{63}$. Dewatered dewage sludge may produce biomass oil combustible gas and coke if oxygen is isolated. Syngas, coke, and tar could be gasified from dewatered dewage sludge under the atmosphere of part oxygen participation. dewatered dewage sludge may be burned to generate heat and get into the next substance form through exhaust gas and ash if the temperature is enough high and oxygen is excessive. the possible pyrolysis product of dewatered dewage sludge is shown in Table 1 and Tables S3-S9 ${ }^{64}$ (in the supporting information) based on literatures and our former researches.

Comparing to the report of 12 key platform chemicals from biomass, which was released by the Pacific Northwest National Key Laboratory and National Renewable Energy Laboratory of America (Fig. 3) ${ }^{65,66}$, we find that the pyrolysis products of dewatered sewage sludge not only includes in essential platform chemicals like glycerol etc. , essential chemical middle product like levoglucosan, and terminal function chemicals like pyridine or 4-acetylaminopyridine also could be produced.

In summary, the downstream research of sludge focuses on the preparation of biochar from sludge and its application ${ }^{67-72}$, energy and nutrient recovery ${ }^{73-76}$, removal of toxic and harmful substances and heavy metals from sludge ${ }^{77-81}$. There are also some reports on the microbial ecological structure of sludge ${ }^{82-84}$, the pyrolysis performance of sludge ${ }^{85-87}$ and its mechanism ${ }^{88-91}$, and even some industrial practices ${ }^{92}$. However, No literatures focusing on the research of production of small molecular chemicals from sewage sludge directly, and the only few papers focused on the use of fermentation mean ${ }^{93-97}$. The use of heterogeneous catalysis has not been reported, so this paper might be the first paper to systematic study the possibility of produce small molecular chemicals from sewage sludge.

This paper will report the catalytic cracking and hydrogenation of dewatered sewage sludge by coupling the molecule and its gather state level and biologic level to produce small molecular chemicals, and the effect of sewage sludge source, effect of catalyst and effect of solvent will be discussed carefully from different perspectives.

Three innovations will be done in this paper:

1. Catalytic cracking technology will be applied to the systematic research of dewatered dewage sludge to manufacture high value chemicals, it is hopeful to achieve the target that resource of dewatered dewage sludge to produce high added value chemistry molecule substance, and make the course of generation of dewatered dewage sludge become a purposeful resource regeneration course, and following propelthe technical routes of disposal and treatment of dewatered dewage sludge become greener and more sustainable.

2. In this technology treatment course, overwhelming majority fraction of dewatered dewage sludge will be transferred into organic chemistry substance, and the heavy metal in dewatered dewage sludge will be naturally enriched and it is possible that it participates in the course of catalysis cracking of dewatered dewage sludge and thereby decrease the dosage of exogenous catalyst and decrease the cost of catalyst preparation and reclaim in the treatment course. At the same time, the heavy metal residue could be reclaimed as a heavy metal resource when the enrichment of heavy metal arrives at to a high level. therefore, the heavy metal in 


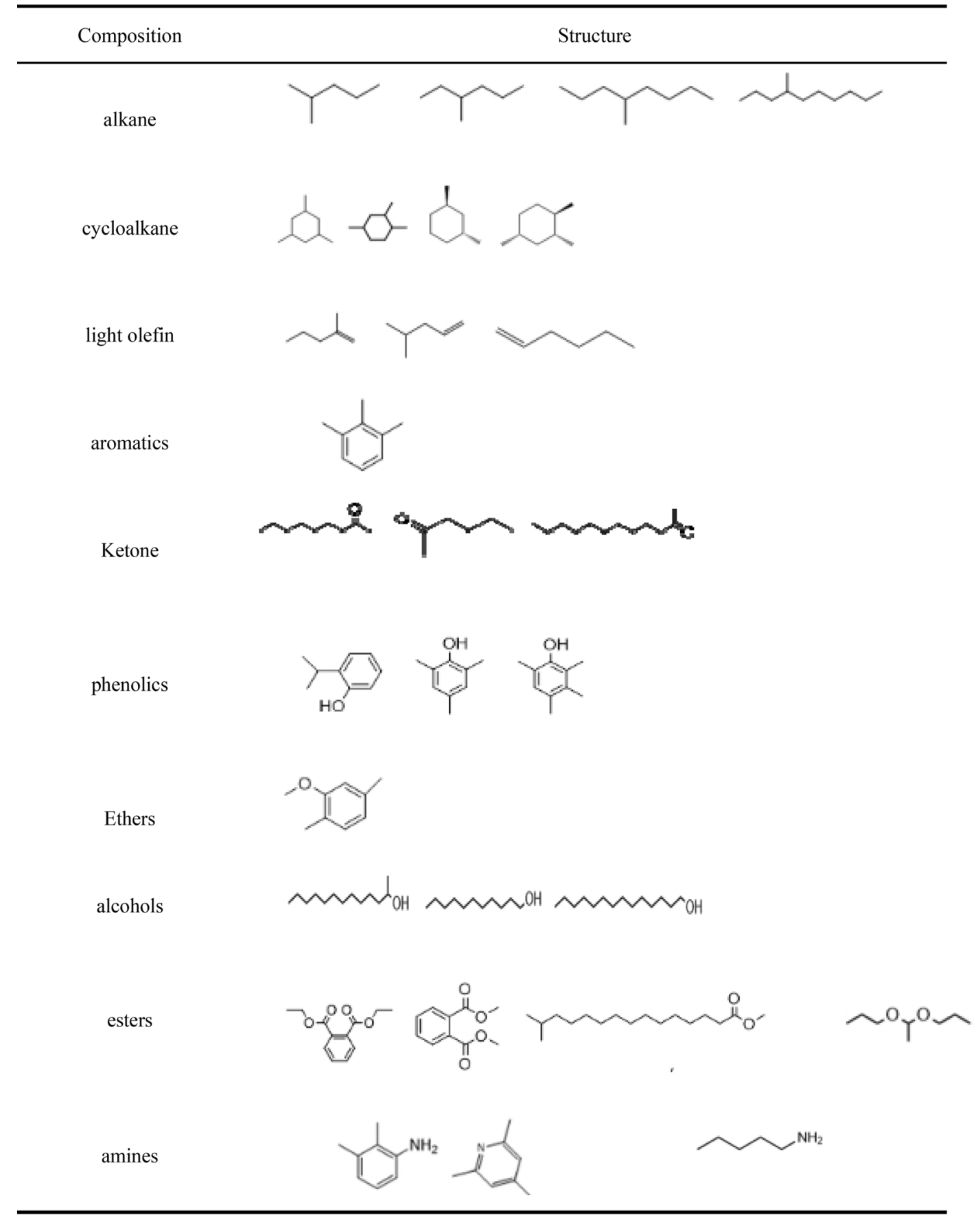

Table 1. Main components of liquid products of catalytic cracked of sewage sludge.

dewatered dewage sludge which applied this method is not any more an environmental risk factor, while it becomes to a valuable or even higher value resource what is sustainable and geener.

3. There is no special condition need to be arrived for the moisture of dewatered dewage sludge in this technology route. On the contrary, the moisture in the dewatered dewage sludge could get into the chemistry molecule as a reactant and thereby avoid the high cost for the dewatering and drying of dewatered dewage sludge in the present disposal method, and the entire atomic economy for the reaction also could be improved.

The most difficult of this research is that the cracking of dewatered dewage sludge relate to a complicated gas-liquid-solid three phase reaction, therefore the commixture and solid to solid mass transfer between dewatered dewage sludge and catalyst maybe become a bottleneck for the enhancement of reactivity and selectivity if heterogeneous catalyst is used. But based on our research on humin (Wang, Y., et al., Catalytic Hydrotreatment of Humins in Mixtures of Formic Acid/2-Propanol with Supported Ruthenium Catalysts. ChemSusChem, 2016. 
$\mathrm{OH}$

ethanol<smiles>OCC(O)CO</smiles>

glycerol<smiles>C=CC(=C)C</smiles>

isoprene<smiles>CC(=O)CCC(=O)O</smiles>

levulinic acid<smiles>OC[C@@H](O)[C@@H](O)[C@H](O)[C@H](O)CO</smiles><smiles>O=C(O)CCO</smiles>

3-hydroxypropanoic acid<smiles>O=C(O)CCC(=O)O</smiles>

succinic acid<smiles>OC(O)C(O)C(O)O</smiles>

xylitol<smiles>O=Cc1ccc(CO)o1</smiles><smiles>CC(O)C(=O)O</smiles>

latic acid

Figure 3. Revised top 12 biobased platform chemicals ${ }^{25}$.

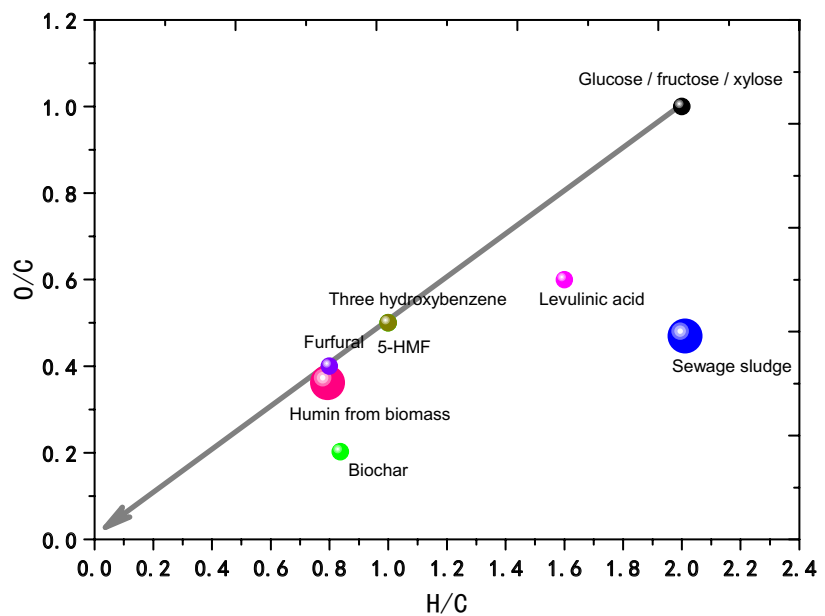

Figure 4. A van Krevelen plot depicting the changes in $\mathrm{H} / \mathrm{C}$ and $\mathrm{O} / \mathrm{C}$ ratio during acid-catalysed dehydration of sugars: carbohydrates (black squares), LA (grey squares), HMF and TB (grey triangles), FF (black triangles), water-soluble products and oligomers (black diamonds), humins (grey diamonds), and biochar (black dots). The elemental dehydration reaction is depicted by the grey arrow. The insert shows a magnification of the elemental composition of humins prepared from different feedstocks: gluc $=$ glucose, fruc $=$ fructose, and $\mathrm{xyl}=\mathrm{xylose}$.

9(9): pp. 951-961), which is a biomass with similar nature to dewatered dewage sludge (Fig. 4). It is obvious that dewatered dewage sludge has higher $\mathrm{O} / \mathrm{C}$ and $\mathrm{H} / \mathrm{C}$, which enunciate that dewatered dewage sludge has higher catalysis transformation potency than humin. Our research of catalysis crack of humin showed that its transfer rate is up to $77 \%{ }^{98}$, so it is possible that the catalysis cracking of dewatered dewage sludge could arrive at higher transfer rate.

In this paper, we report a detailed study on the dewage sludge depolymerisation with heterogeneous catalysts in combination with the effect of the source of dewage sludge, which is a sign of the effect of the microbiology structure, and a hydrogen source (molecular hydrogen, formic acid (FA), isopropanol (IPA)) also was studied in this research. Initial experiments were conducted at standard conditions and the product oils were quantified and characterised in detail using advanced GC techniques and GPC. Subsequently, the effect of microbiology structure was analyzed by 16 SrRNA analysis. 


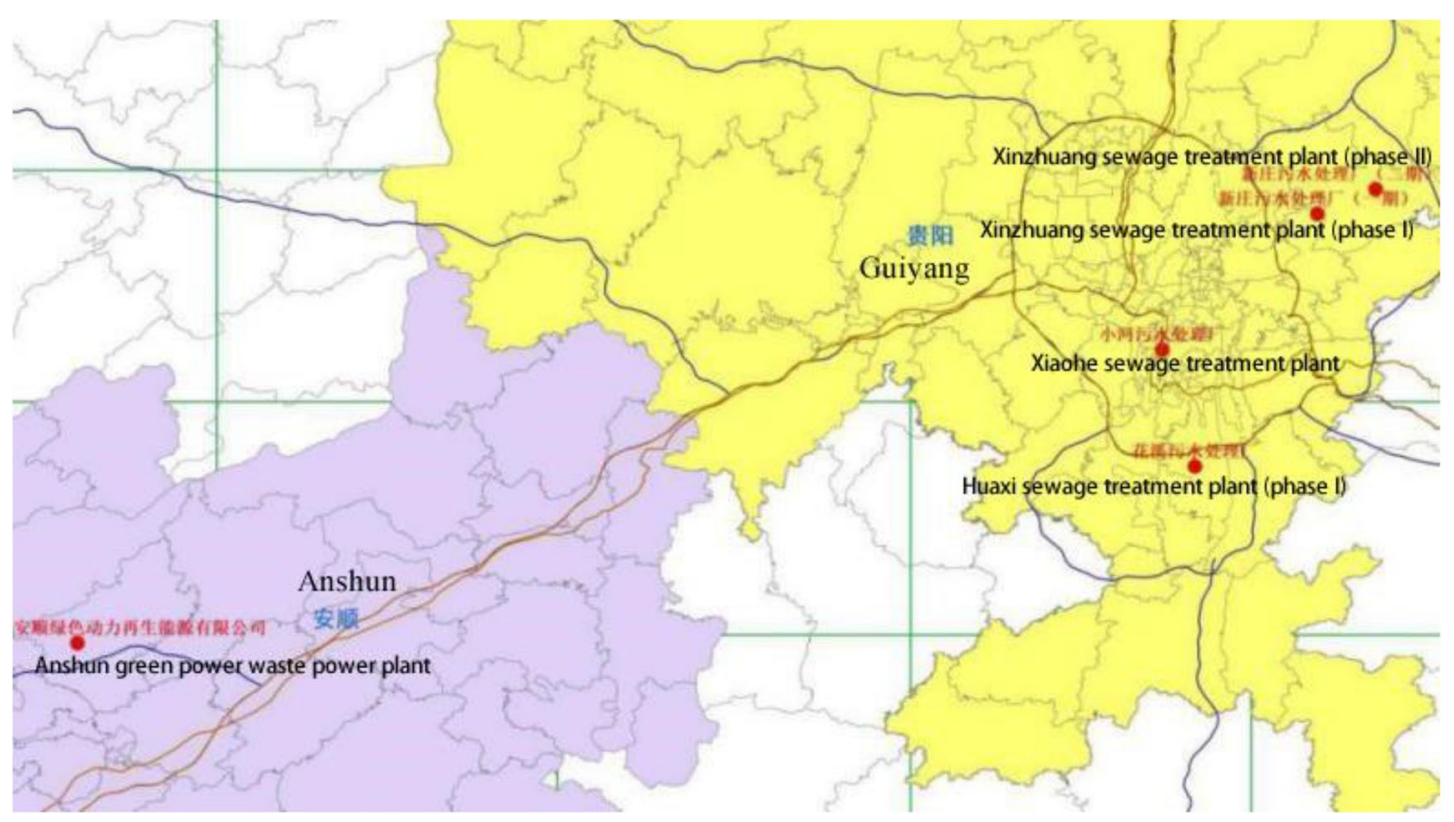

Figure 5. Distribution of sampling points of sewage sludge (Draw with ArcGIS 10.2 for Desktop Version:10.2.0.3348).

\begin{tabular}{|l|l|l|}
\hline No. & Name of sewage treatment plant & Nature \\
\hline T-1 & Huaxi sewage treatment plant & Aerobic \\
\hline T-2 & Xinzhuang wastewater treatment plant (phase 1) & Aerobic \\
\hline T-3 & Xinzhuang wastewater treatment plant (phase 1) & Anaerobic \\
\hline T-4 & Xiaohe sewage treatment plant & Aerobic \\
\hline T-5 & Anshun green power waste power plant & Aerobic \\
\hline T-6 & Anaerobic biological purification sample & Anaerobic \\
\hline T-7 & Anshun green power waste power plant & Anaerobic \\
\hline
\end{tabular}

Table 2. 16SrRNA high-throughput analysis samples.

\begin{tabular}{|l|l|l|}
\hline Name & No. & Manufacturer \\
\hline $\begin{array}{l}\text { Platinum carbon catalyst } \\
\text { Water content }<80 \%\end{array}$ & $\mathrm{Pt} / \mathrm{C} 1$ & Shanghai McLean Biochemical Technology Co., Ltd \\
\hline Platinum carbon catalyst (Mw) & $\mathrm{Pt} / \mathrm{C} 2$ & Shanghai McLean Biochemical Technology Co., Ltd \\
\hline Palladium carbon catalyst & $\mathrm{Pd} / \mathrm{C}$ & Shanghai McLean Biochemical Technology Co., Ltd \\
\hline Ruthenium carbon catalyst & $\mathrm{Ru} / \mathrm{C}$ & Tianjin Hiens Biochemical Technology Co., Ltd \\
\hline Iridium carbon catalyst & $\mathrm{Ir} / \mathrm{C}$ & Shanghai McLean Biochemical Technology Co., Ltd \\
\hline Rhodium carbon catalyst & $\mathrm{Rh} / \mathrm{C}$ & Shanghai Myrel Chemical Technology Co., Ltd \\
\hline
\end{tabular}

Table 3. Catalysts tested in this research.

\section{Materials and methods}

Firstly, a standard experiment condition, $30 \mathrm{~g}$ IPA, $0.100 \mathrm{~g} \mathrm{Ru} / \mathrm{C}, 2.000 \mathrm{~g}$ sewage sludge were set up to test the effect of source of sewage sludge, effect of catalyst and effect of solvent. The sewage sludge tested were shown in Fig. 5, which were got from Xinzhuang sewage treatment factory (Phase I and Phase II), Huaxi sewage treatment factory, Xiaohe sewage treatment factory and Anshun green power renewable energy Co., Ltd (Fig. 8), which included all type of dewatered sewage sludge source around Guiyang city.

Here we took Huaxi sewage treatment factory as an example to explain it carefully in the supporting information, and the information of other sample source could be found by contacting the authors.

16SrRNA analysis for the sewage sludge was used to help to appraise the effect of biology, and the samples were listed in Table 2. Catalyst tested were shown in Table 3 and the solvents tested were shown in Table 4. 


\begin{tabular}{|l|l|}
\hline No. & Solvent \\
\hline 1 & Isopropanol \\
\hline 2 & Ultra-pure water \\
\hline 3 & Isopropanol + formic acid \\
\hline 4 & Isopropanol + methanol \\
\hline 5 & Isopropanol + ethanol \\
\hline
\end{tabular}

Table 4. Solvents tested in this research.

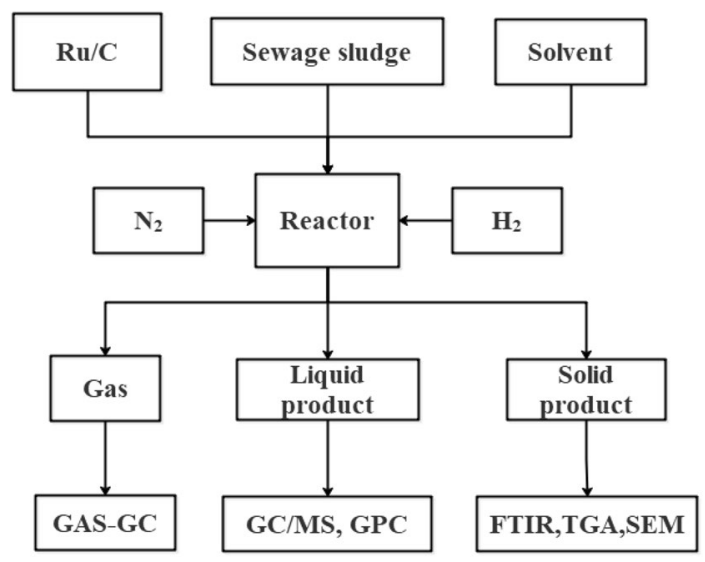

Figure 6. Overview of the experimental procedure for a catalytic liquefaction experiment.

Chemicals. All chemicals used in this work were of analytical grade and used without further purification. Some of the chemicals were obtained from the companies listed in Table 3 . The catalyst was not pre-activated and used as such.

More information for some chemicals is listed in the supporting information.

Catalytic pyrolysis of sludge. Firstly the sludge was pretreated with this process: Weigh $200 \mathrm{~g}$ of sludge, put it in a $500 \mathrm{~mL}$ beaker and seal it with plastic wrap, cut a few holes on the plastic wrap with scissors, place it in a freeze dryer for $48 \mathrm{~h}$, and take it out after vacuum drying. Crush the sludge with a grinder and put it into a beaker and seal it with plastic wrap.

The hydrogenation experiments were performed in a whf- 0.1 laboratory magnetic stirring reactor and its parameters were shown in Table S1 (in the supporting information). The whf series laboratory magnetic stirring reactor is a stirring reaction device for chemical reaction of liquid-liquid, gas-liquid, liquid-solid or gas-liquid-solid three-phase chemical materials, which can make chemicals stir well under the given pressure and temperature to enhance the mass and heat transfer.

A representative example of an experiment is schematically given in Fig. 6:

Dehydrated compressed medicated sewage sludge from Huaxi Sewage Treatment Plant which has been freezedried beforehand: $2.00 \mathrm{~g}$;

Catalyst: $0.100 \mathrm{~g}$;

Solvent: $30.000 \mathrm{~g}$ isopropanol for the reseaches of the effect of catalyst and sewage sludge source, and in the reseach of solvents it was set in the ratio of the fellowing data:

First time: $30.000 \mathrm{~g}$ isopropanol;

Second time: $30.000 \mathrm{~g}$ ultrapure water;

Third time: isopropanol: $9.000 \mathrm{~g}$, formic acid: $9.000 \mathrm{~g}$;

Fourth time: isopropanol: $9.000 \mathrm{~g}$, methanol: $9.000 \mathrm{~g}$;

Fifth time: isopropanol: $9.000 \mathrm{~g}$, ethanol: $9.000 \mathrm{~g}$.

The standard operation process is shown in the supporting infromation.

Product collection includes gas phase, liquid phase, and solid phase:

1. Gas phase products: After the reaction is finished, connect a $1 \mathrm{~L}$ gas bag to the gas release valve, and slowly open the gas collection valve to deflate until the gas bag bulges. After collection, store it for backup and measure the gas volume by drainage method. 
2. Liquid phase-solid phase product: when the pressure gauge shows that the pressure is 0 , open the reactor, and collect the mixture in the reactor with a well-centrifuge tube; put it into the centrifuge and set the centrifuge speed at $5000 \mathrm{rpm}, \mathrm{t}=30 \mathrm{~min}$, and then start centrifuge, collect the supernatant after centrifugation in a $20 \mathrm{ml}$ sample bottle (that is, the liquid phase), put the remaining sludge in an oven at $75^{\circ} \mathrm{C}$ for $48 \mathrm{~h}$, and leave the remaining material after drying, which is the solid phase product.

The analytical methods were shown in the sourpporting in formation.

Definitions. 1. Calculation of sludge conversion rate

$$
n=\frac{m_{1}-\left(M-m_{2}-m_{3}\right)}{m_{1}} * 100 \%
$$

where $n$, sludge conversion rate; $M$, total weight of dried sewagle sludge sample, catalyst and centrifuge tube, g;

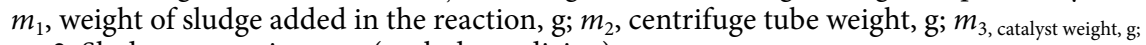

2. Sludge conversion rate (exclude medicine)

Before the dehydration of sewage sludge, drugs are usually added in the sewage sludge for dehydration pretreatment. So, the pyrolyzed sludge which were collected directly from the plants usually contain some drugs, which will affect the conversion rate of catalytic hydropyrolysis of sewage sludge.

Because Huaxi Sewage Treatment Plant, Xiaohe Sewage Treatment Plant and Anshun Green Powered Waste Incineration Power Plant used pam (polyacrylamide) as the agent, the dosage ratio was 1/1000, so the effect of the agent on the results was negligible. However, the chemical used in Xinzhuang Sewage Treatment Plant is lime, and the dosage is 0.2 , and the possible forms of lime after adding sludge are calcium hydroxide, calcium carbonate, and calcium oxide. Since calcium carbonate is cracked into calcium oxide and carbon dioxide at $800-900{ }^{\circ} \mathrm{C}$, the pyrolysis temperature of calcium oxide is higher than $900^{\circ} \mathrm{C}$, while the maximum pyrolysis temperature in these experiments is $360^{\circ} \mathrm{C}$. Therefore, the quality of the dehydrating agent remains the same before and after the experiments. So the dosage of the added agent he Xinzhuang Sewage Treatment Plant has a large effect on the conversion rate. So we recalculate the conversion rate.

Calculation was performed like this:

$$
n=\frac{m_{1} *(1-0.2)-\left(M-m_{2}-m_{3}\right)}{m_{1} *(1-0.2)} * 100 \%
$$

where $n$, sludge conversion rate; $M$, total weight of dried sewage sludge sample, catalyst and centrifuge tube, g; $m_{1}$, weight of sludge added in the reaction, g; $m_{2}$, centrifuge tube weight, g; $m_{3}$, catalyst weight, g; 0.2 , lime dosing ratio in sewage sludge.

3. Sludge conversion rate (after deducting the moisture in the sludge and the effect of adding chemicals)

Because there is some free water and cell-bound water in the sludge, the conversion rate of the sludge pyrolysis should be deducted from the effect of water. The conversion rate of the sludge after deducting the addition of chemicals and water is shown as follows:

$$
\gamma=\left(1-\frac{M-m_{1}-m_{2}}{m *(1-\lambda) *(1-\kappa)}\right) * 100 \%
$$

where $\gamma$, Sludge conversion rate; $M$, sludge pyrolysis drying solid phase, catalyst and centrifuge tube total, $g$; $m$, the mass of sludge added to the reaction, $g ; m_{1}$, centrifuge tube weight, g; $m_{2}$, catalyst weight, g; $\lambda$, sludge moisture content which is derived from the TGA data; $\kappa$, the input ratio of sludge dehydration agent, Xinzhuang Sewage Treatment Plant Phase I and Phase II are $C_{a} O, 200 \mathrm{~kg} / \mathrm{t}$, that is, the dosing ratio is 0.2 . The remaining three sewage treatment plants are dosed with PAM (polyacrylamide), and the dosing ratio is $1 / 1000$, which can be ignored the dosage of the agent.

\section{Results and discussion}

Sewage sludge characterization. Microbial diversity of sewage sludge. rRNA is highly conserved in nucleotide evolution, advanced structure, base composition, and biological functions in the biological evolution process, so it is called bacterial "fossil". This conservation has made rRNA into the current classification of environmental microorganisms. The most useful and commonly used "Molecular Chronograph".

Prokaryotic microorganisms contain three types of rRNA, 23SrRNA, 16SrRNA, and 5SrRNA, among which 16SrRNA is a small subunit ribosomal RNA with a moderate molecular weight and is an ideal research object. The basic principle of 16SrRNA sequence analysis technology is to extract 16SrRNA from environmental microorganism samples The $16 \mathrm{~S}$ rRNA sequence information is obtained by cloning, sequencing or enzyme digestion, and probe hybridization, and then compared with the sequence data or other data in the 16S rRNA database to identify the types of microorganisms that may be present in the sample.

The chart data for this analysis comes from Shanghai Meiji Cloud Platform (http://www.i-sanger.com).

1. Bacterial analysis

The bacterial and archaea diversity index of urban sludge is shown in Table 5 .

The bacterial community abundance is shown in Fig. 7:

2. Archaeal analysis

Archaea diversity indicators of sewage sludge are shown in Table 6:

Archaea community abundance is shown in Fig. 8: 


\begin{tabular}{|l|r|r|r|l|l|l|}
\hline Sample name & \multicolumn{1}{|l|}{ OTU } & \multicolumn{1}{l|}{ ACE } & \multicolumn{1}{l|}{ Chaos } & Shannon & Simpson & Coverage \\
\hline Anshun green powered waste incineration power plant (anaerobic) & 227 & 238.72 & 238.55 & 3.34 & 0.07385 & 0.99931 \\
\hline Anshun green powered waste incineration power plant (aerobic) & 13 & 19.27 & 13.50 & 1.15 & 0.37068 & 0.99994 \\
\hline Huaxi sewage treatment plant (aerobic) & 1724 & 1951.19 & 1972.01 & 6.16 & 0.00579 & 0.98869 \\
\hline Xinzhuang wastewater treatment plant (phase i, anaerobic sample) & 1929 & 2143.93 & 2162.53 & 5.94 & 0.00753 & 0.99354 \\
\hline Xinzhuang wastewater treatment plant (phase I, aerobic sample) & 1911 & 2111.99 & 2109.60 & 6.07 & 0.00608 & 0.99289 \\
\hline Xiaohe sewage treatment plant (aerobic sample) & 1591 & 1810.65 & 1833.63 & 5.94 & 0.00704 & 0.98928 \\
\hline
\end{tabular}

Table 5. Bacterial diversity index table.

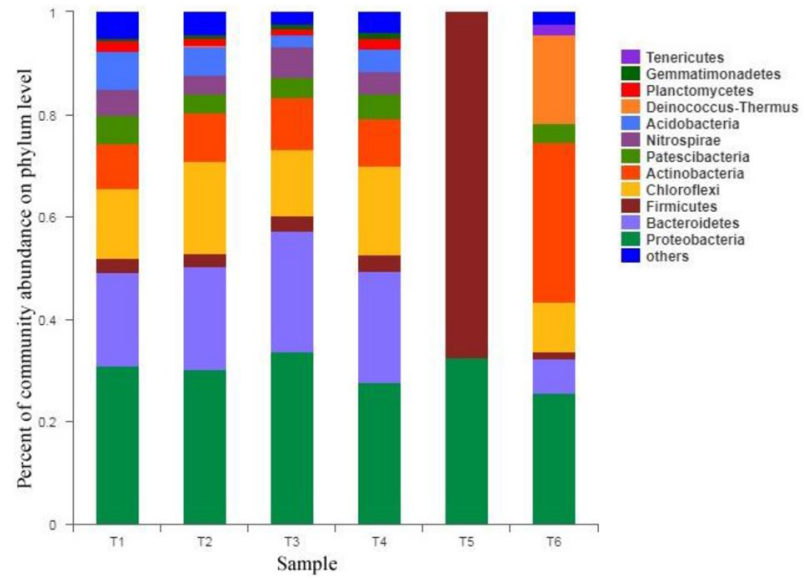

Figure 7. Proportion of bacterial phylum classification abundance/phylum abundance of bacterial.

\begin{tabular}{|l|l|l|l|l|l|l|}
\hline Sample name & OTU & ACE & Chaos & Shannon & Simpson & Coverage \\
\hline Anshun green powered waste incineration power plant (anaerobic) & 61 & 68.99 & 66.63 & 1.25 & 0.44 & 0.99971 \\
\hline Anshun green power waste incineration power plant (aerobic sample) & - & - & - & - & - & - \\
\hline Huaxi wastewater treatment plant (aerobic sample) & 125 & 144.85 & 142.25 & 2.19 & 0.25 & 0.999271 \\
\hline Xinzhuang wastewater treatment plant (phase I, anaerobic sample) & 233 & 248.26 & 240.88 & 2.56 & 0.23 & 0.998756 \\
\hline Xinzhuang wastewater treatment plant (phase I, aerobic sample) & 153 & 164.33 & 160.43 & 2.96 & 0.10 & 0.99925 \\
\hline Xiaohe sewage treatment plant (aerobic sample) & 199 & 225.58 & 217.50 & 1.74 & 0.43 & 0.998922 \\
\hline Anaerobic purification of samples & 49 & 58.04 & 58.00 & 0.65 & 0.76 & 0.999601 \\
\hline
\end{tabular}

Table 6. Archaea diversity index table.

The ACE and Chaos indexes in the table are the microorganisms in the sludge. For the abundance index of the community, the higher the index value is, the higher the richness of the bacteria in the sludge; the Coverage index represents the coverage of each sample library. If the Coverage index is closer to 1, the test result is closer to the actual sample. Results; Shannon and Simpson indices reflect the diversity of microbial communities in the sample.

Real structure; from the perspective of the OTU index, the number of archaea and bacterial microorganisms in several sewage treatment plants are sorted in descending order: Xinzhuang sewage treatment plant, Xiaohe sewage treatment plant, Huaxi sewage treatment plant, Anshun green power waste incineration Power plants; judging from the ACE and Chaos indexes, the order of bacteria and archaeal abundance in several sewage treatment plants shows a consistent rule, from high to low: Xinzhuang sewage treatment plant, Xiaohe sewage treatment plant, Huaxi sewage treatment plant, Anshun green power waste incineration power plant; judging from the Shannon index, the archaeal biodiversity of each sewage treatment plant is Xinzhuang Wastewater Treatment Plant, Huaxi Wastewater Treatment Plant, Xiaohe Wastewater Treatment Plant, and Anshun Green Power Waste Incineration Power Plant. The bacterial biodiversity in descending order is: Huaxi Wastewater Treatment Plant, Xinzhuang Wastewater Treatment Plant, Xiaohe Wastewater Treatment Plant, Anshun Green Power Waste Incineration Power Plant; According to the Simpson index, the proportion of the detected bacteria and archaea in the total microorganisms in descending order is: Anshun Green Powered Waste Incineration Power Plant, Xiaohe Sewage Treatment Plant, Huaxi Sewage Treatment Plant, and Xinzhuang Sewage Treatment Plant. 


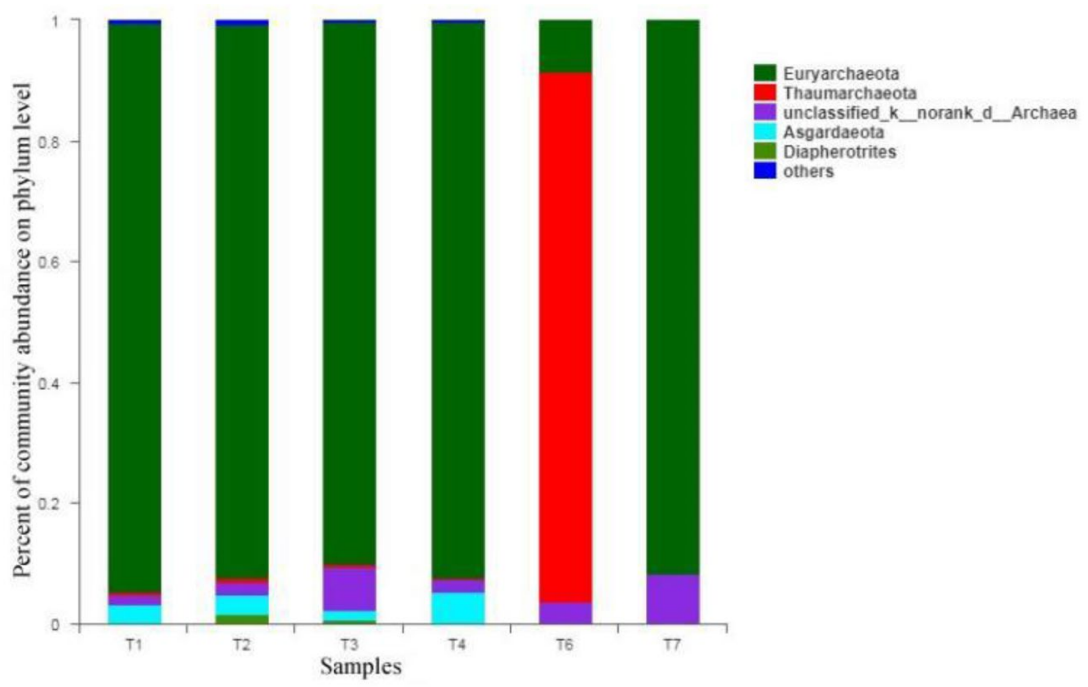

Figure 8. Proportion of Archaea taxonomy abundance.

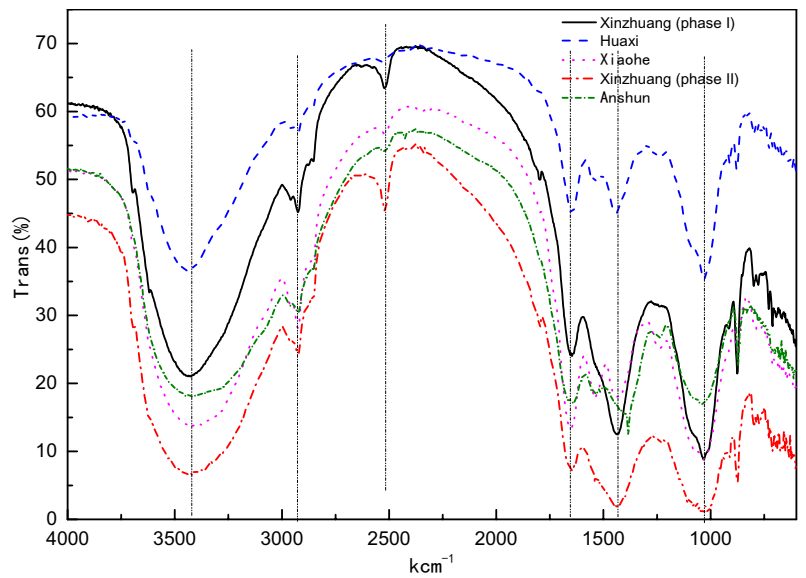

Figure 9. Infrared spectrum of sewage sludge.

Pyrosequencing results of bacterial and archaeal communities were shown in Table 6. The OTUs for bacteria obtained from different samples were 227,13,1724,1929,1911,1591 respectively. For archaeal, OTUs of the samples were communities 61, -, 125,233,153,199,49, excluding the Ansun sample (aerobic). The observed ACE and Chao showed that almost all phylotypes could be found in the samples. The coverage of both communities was also over $98 \%$, which indicated that the sequencing results are reasonable.

Shannon and Simpson indices were used to estimate the samples' community diversities. High Shannon index is a signal of more diverse for the microbial community, while Simpson index should be low. Here Shannon and Simpson index were almost the same except for Ansun samples. There were the lowest Shannon index and highest Simpson index in these samples showed that their bacterial diversity was the lowest.

Archaeal diversity of the Ansun sample (anaerobic) and Xiaohe sample (aerobic) was lower than that of other samples. Shannon and Simpson indexes for Ansun sample (anaerobic) and Xiaohe sample (aerobic) were 1.25 with 1.74 and 0.44 with 0.43 . Other samples had almost the same value from 2.19 to 2.96(Shannon index) and from 0.10 to 0.23 (Simpson index).

FTIR characterization. Fourier transform infrared spectroscopy (FTIR) can perform qualitative analysis of substances, and functional groups on the surface of the sewage sludge may adsorb some impurities, so it is necessary to perform FTIR analysis on the sewage sludge.

Infrared spectra of sewage sludge samples from various sewage treatment plants are shown in Fig. 9:

Based on the OMNIC analysis for the FTIR data of sewage sludge, the functional groups of each sewage sludge from different source are shown in Table 7:

Based on the analysis of Fig. 10, it is concluded that all of the samples from the five sewage treatment plants have a relatively strong absorption peak between $3000 \mathrm{~cm}^{-1}$ and $3750 \mathrm{~cm}^{-1}$, which is due to the characteristic peak 


\begin{tabular}{|l|l|}
\hline Sewage sludge treatment plant & Functional group \\
\hline Huaxi sewage treatment plant & Primary aliphatic amides, inorganic phosphates, primary aliphatic alcohols \\
\hline Xinzhuang wastewater treatment plant (phase 1) & Inorganic carbonate, inorganic phosphates, primary aliphatic alcohols \\
\hline Xinzhuang wastewater treatment plant (phase II) & Inorganic carbonate, inorganic phosphates, primary aliphatic alcohols \\
\hline Xiaohe sewage treatment plant & Inorganic phosphates, aliphatic secondary amides, primary aliphatic alcohols \\
\hline Anshun green power waste power plant & Inorganic nitrites, primary aliphatic amides \\
\hline
\end{tabular}

Table 7. Summary of functional groups in sewage sludge from different source.

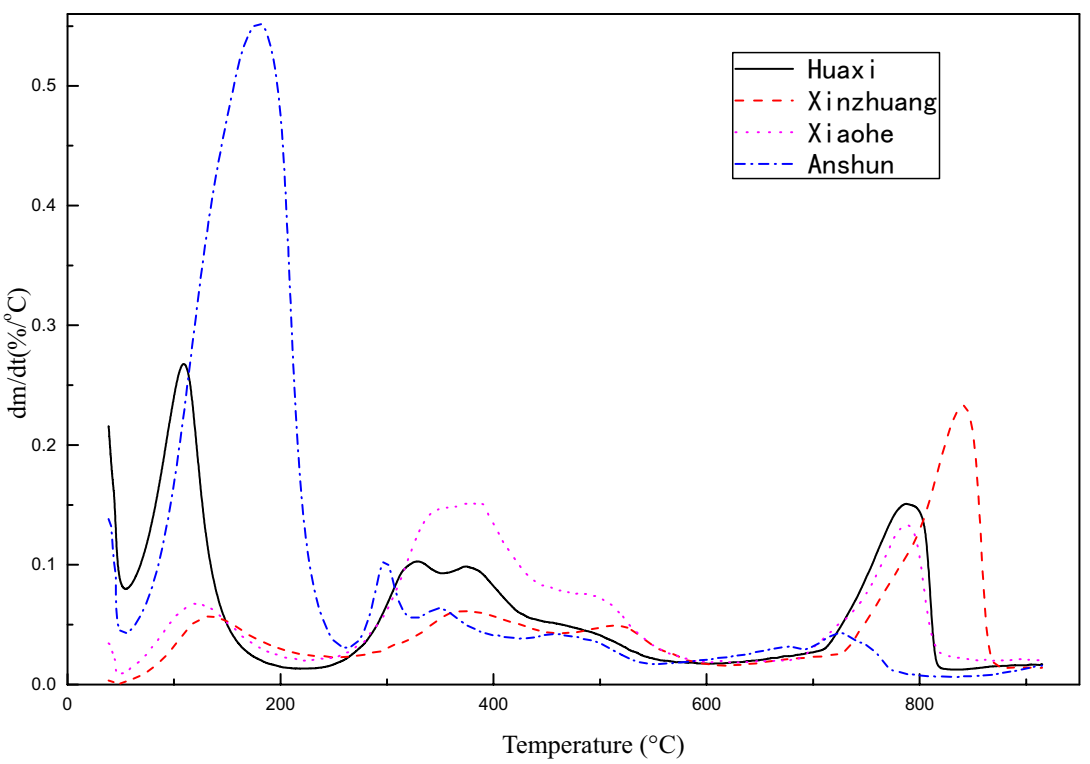

Figure 10. Sludge dtg diagram.

of $-\mathrm{NH}$ and $-\mathrm{OH}$ stretching vibration; $3000 \mathrm{~cm}^{-1}$ is the absorption band that formed by $-\mathrm{CH}$ in aromatic hydrocarbons and $-\mathrm{CH}_{3},-\mathrm{CH}_{2}$ stretching vibration in aliphatic ${ }^{99}$; The absorption band at about $2500 \mathrm{~cm}^{-1}-2650 \mathrm{~cm}^{-1}$ is formed due to $-\mathrm{SH}$ stretching vibration; the absorption peak at $1600 \mathrm{~cm}^{-1}-1900 \mathrm{~cm}^{-1}$ is mainly due to the characteristic peak of $\mathrm{C}=\mathrm{O}$ stretching vibration ; Peak at $1200 \mathrm{~cm}^{-1}$ is the characteristic absorption peak of $\mathrm{COC}, \mathrm{CO}$ stretching vibration and $-\mathrm{OH}$ flexural vibration in alcohol, phenol, and carboxylic acid; the absorption bands at about $1100 \mathrm{~cm}^{-1}$ are $\mathrm{Si}-\mathrm{OC}$ or $\mathrm{Si}-\mathrm{O}-\mathrm{Si}$ stretching vibration peak. From the FTIR diagram of the sludge in Fig. 10, we can see that there is a strong resolution band around $1000 \mathrm{~cm}^{-1}$, which may be due to -CO stretching and $-\mathrm{OH}$ deformation vibration, at $1500 \mathrm{~cm}^{-1}$, the surrounding absorption peak and a band at about $1600 \mathrm{~cm}^{-1}$ are formed by $\mathrm{CH}$ bending vibration and $\mathrm{C}=\mathrm{C}$ stretching vibration, so it can be proved that aromatics and phenyl groups exist, and the peak around $1600 \mathrm{~cm}^{-1}$ is not only related to $\mathrm{N}=\mathrm{N}$, it also related to aliphatic nitro and nitroso compounds ${ }^{13}$ At about $3500 \mathrm{~cm}^{-1}$, there is a broad absorption peak, which means that there are lots of hydroxyl groups, which indicates that the molecules contains amide components, because the $\mathrm{NH}$ tensile vibration at about $3500 \mathrm{~cm}^{-1}$ and the $1600 \mathrm{~cm}^{-1}$ Carbonyl $\mathrm{C}=\mathrm{O}$, and the peaks generated by $\mathrm{NH}$ shear and $\mathrm{CN}$ tensile vibration around $1400 \mathrm{~cm}^{-1}$ can prove the presence of amide components ${ }^{14}$.

TGA characterization. The thermogravimetric curve of sewage sludge from different source were shown in Fig. 10:

It is known from Fig. 11 that all the samples have a high weight loss rate at $100{ }^{\circ} \mathrm{C}$. Because the gasification temperature of water is $100^{\circ} \mathrm{C}$, it can be determined that the peak that occurs there is caused by water loss; The peaks appearing at $200-500^{\circ} \mathrm{C}$ are the pyrolysis of organic matter in sewage sludge, and the peaks at $700-900{ }^{\circ} \mathrm{C}$ are macromolecular refractory substances such as cellulose and humus(Table 8$)^{100}$.

The thermogravimetric peak trend of all samples is roughly same, but there are also some differences:

1. The sludge from Xinzhuang Sewage Treatment Plant showed a small peak of weight loss before $700{ }^{\circ} \mathrm{C}$. This is because Xinzhuang Sewage Treatment Plant added lime with a dosing ratio of 0.2 during the sludge treatment. A large amount of heat makes the water and some organic matter in the sludge less decomposed, and the proportion of non-degradable organic matter in the sludge increases, so the peak of weight loss rate of other sewage treatment plants appears around $800^{\circ} \mathrm{C}$; 


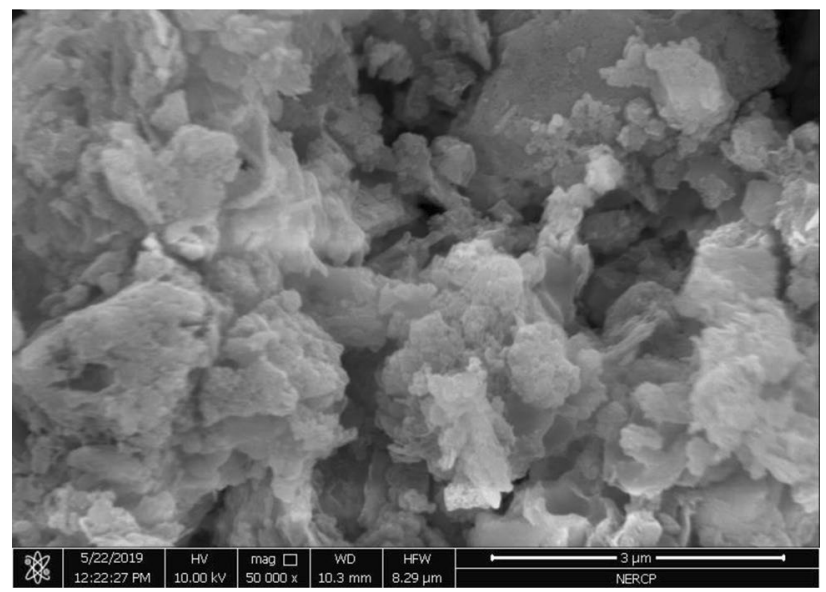

Figure 11. Electron microscope scan of dried sludge.

\begin{tabular}{|l|l|l|l|l|}
\hline Temperature $/{ }^{\circ} \mathbf{C}$ & $\mathbf{5 0 - 1 5 0}$ & $\mathbf{1 5 0 - 5 3 0}$ & $\mathbf{5 3 0 - 6 7 0}$ & $\mathbf{7 0 0 - 9 0 0}$ \\
\hline Decompose matter & Water & Volatile matter & Fixed carbon & Refractory organic matter \\
\hline
\end{tabular}

Table 8. Sludge combustion weightless substances-temperature correspondence table.
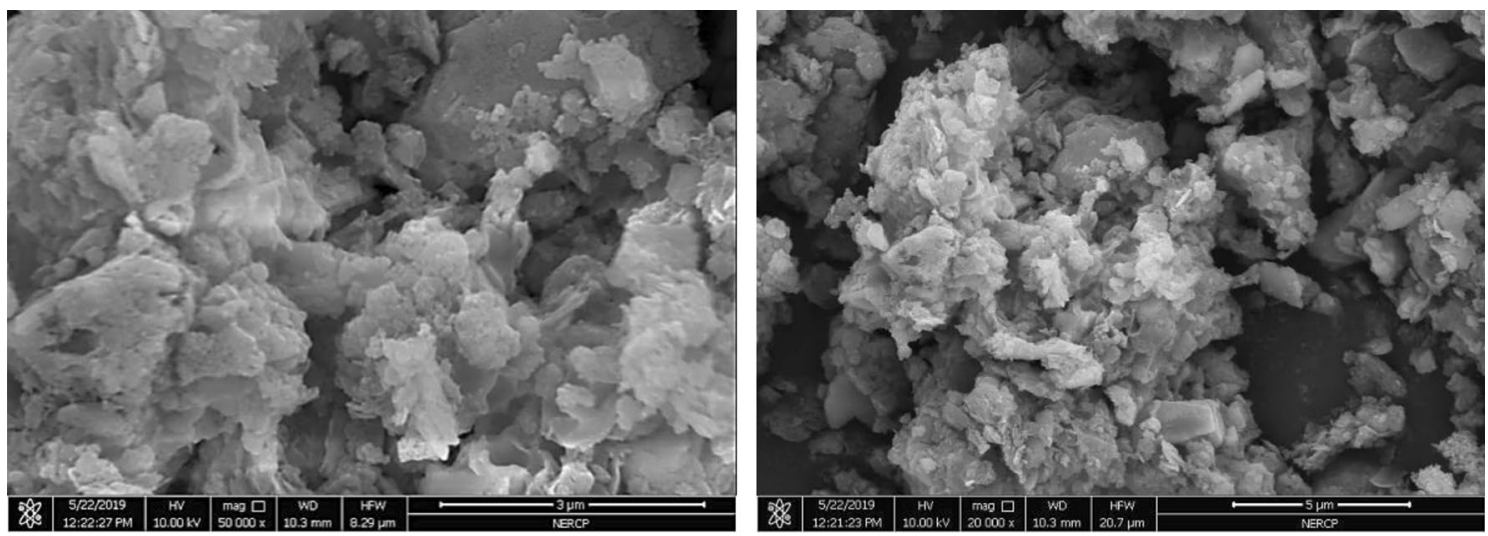

Figure 12. Sem diagram of sludge.

2. The samples from Huaxi Sewage Treatment Plant and the Anshun Green Powered Waste Incineration Power Plant showed a more pronounced peak at about $100^{\circ} \mathrm{C}$, which indicates that the decemented samples of the Huaxi Sewage Treatment Plant and the Anshun Green Powered Waste Incineration Power Plant still contain a relatively large proportion of moisture.

3. Sample from Huaxi Sewage Treatment Plant sludge has a smaller weightless peak at $700-900{ }^{\circ} \mathrm{C}$ than other sewage treatment plants, which may be related to the treatment process (sbr) of Huaxi Sewage Treatment Plant, compared with others which is smaller at $700-900^{\circ} \mathrm{C}$, The weightless peak is the Xiaohe Sewage Treatment Plant.The wastewater treatment process is also SBR. It can be concluded that the SBR process contains more microorganisms that can degrade difficult-to-degrade organic substances.

As shown in Fig. 11, when the temperature is in the range of $50-210^{\circ} \mathrm{C}$, the original sludge loses weight due to the evaporation of moisture; when the temperature is in the range of $300-500{ }^{\circ} \mathrm{C}$, the original and external sludge samples are due to fibers and some polymer compounds, etc. Difficult volatile organic compounds are decomposed to show weight loss ${ }^{101}$; When the temperature is around $800{ }^{\circ} \mathrm{C}$, the weight loss of sludge is because the non-biodegradable humus and cell wall fibers are decomposed ${ }^{102}$.

SEM characterization. It can be seen from Figs. 11, 12 and 13 that the dried sludge has the characteristics of lamellar and pore-like characteristics. These characteristics indicate that the specific surface area of the sludge is large and the adsorption performance is good. It can be adsorbed more during the sewage treatment process. More bacteria and organic matter, increasing the treatment effect of the sewage treatment plant. 


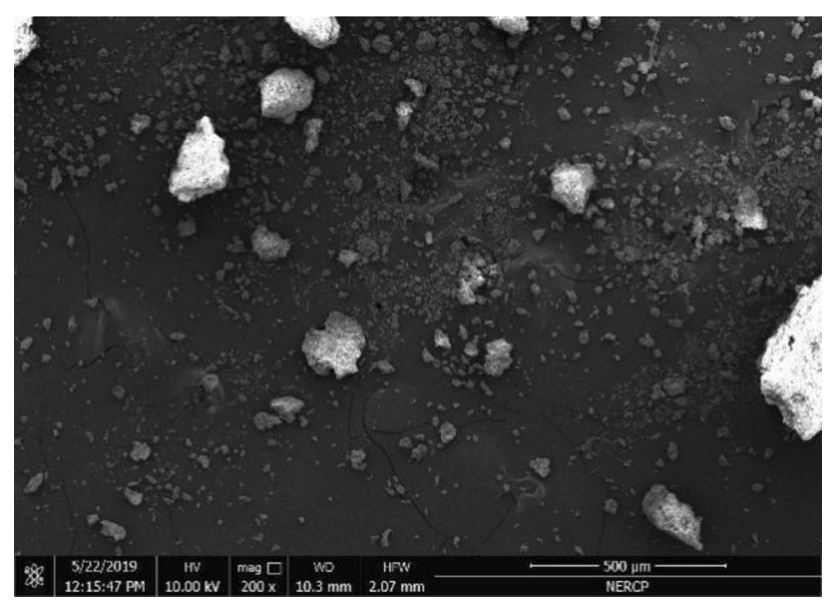

Figure 13. Sem diagram of sludge.

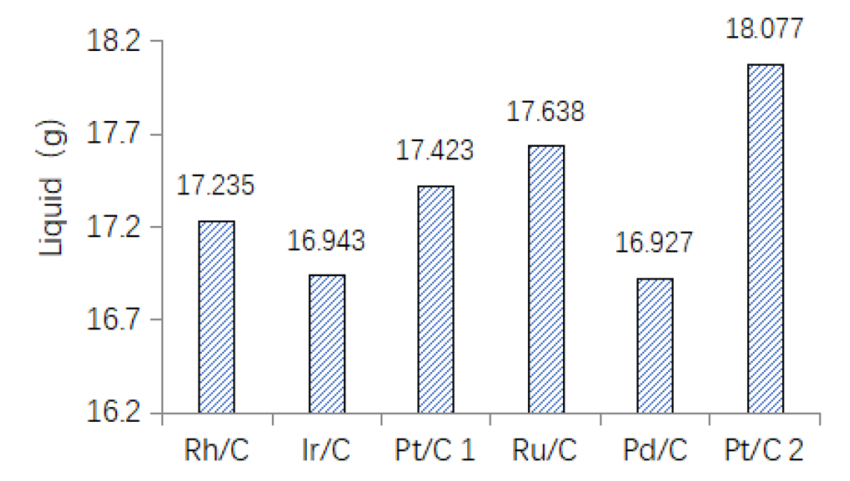

Figure 14. Mass change of liquid product under different catalyst conditions.

\begin{tabular}{|c|c|c|c|c|}
\hline $\begin{array}{l}\text { Huaxi sewage treatment plant } \\
(\%)\end{array}$ & $\begin{array}{l}\text { Xinzhuang wastewater treatment } \\
\text { plant (phase 1) }(\%)\end{array}$ & $\begin{array}{l}\text { Xinzhuang wastewater treatment } \\
\text { plant (phase II) (\%) }\end{array}$ & $\begin{array}{l}\text { Xiaohe sewage treatment plant } \\
(\%)\end{array}$ & $\begin{array}{l}\text { Anshun green power waste } \\
\text { power plant }(\%)\end{array}$ \\
\hline 58.27 & 56.11 & 42.41 & 62.71 & 83.72 \\
\hline
\end{tabular}

Table 9. Urban sludge pyrolysis conversion rate.

\begin{tabular}{|c|c|c|c|c|}
\hline $\begin{array}{l}\text { Huaxi sewage treatment plant } \\
(\%)\end{array}$ & $\begin{array}{l}\text { Xinzhuang wastewater treatment } \\
\text { plant (phase 1) }(\%)\end{array}$ & $\begin{array}{l}\text { Xinzhuang wastewater treatment } \\
\text { plant (phase II) }(\%)\end{array}$ & $\begin{array}{l}\text { Xiaohe sewage treatment plant } \\
(\%)\end{array}$ & $\begin{array}{l}\text { Anshun green power waste } \\
\text { power plant }(\%)\end{array}$ \\
\hline 58.27 & 51.74 & 38.16 & 62.71 & 83.72 \\
\hline
\end{tabular}

Table 10. Sewagle sludge conversion rate after deducting the effect of added chemicals.

Figure 14 is a scanning electron microscope image of the original sludge. It can be seen from the figure that the surface of the mud sample is uneven, the particles are dense and stick together in a mass, and there is basically no microporous structure.

From the Figs. 13 and 14 sludge SEM images, the microstructure of the sludge is nodular and is a large polymer, like foam, with an uneven shape and surface.

Conversion rate of sewage sludge. Conversion rate of sewage sludge from the five sewage treatment plants was shown in Table 9:

Sewage sludge conversion rate (except medicine) was shown in Table 10:

Conversion rate of sewage sludge after exclude the effect of water is shown in Table 11:

Based on the data of Tables 9, 10 and 11, we can see that after the pyrolysis and hydrogenation of sewage sludge, all sewage sludges are cracked into other substances, and the highest conversion rate is $83.72 \%$, which was 


\begin{tabular}{|l|l|l|l|l|l|}
\hline Factory name & $\begin{array}{l}\text { Huaxi sewage treatment } \\
\text { plant (\%) }\end{array}$ & $\begin{array}{l}\text { Xinzhuang wastewater } \\
\text { treatment plant (phase 1) (\%) }\end{array}$ & $\begin{array}{l}\text { Xinzhuang wastewater } \\
\text { treatment plant (Phase II) } \\
(\%)\end{array}$ & $\begin{array}{l}\text { Xiaohe sewage treatment } \\
\text { plant (\%) }\end{array}$ & $\begin{array}{l}\text { Anshun green power waste } \\
\text { power plant (\%) }\end{array}$ \\
\hline Moisture content & 16.448 & 5.329 & 5.329 & 6.563 & 55.329 \\
\hline Conversion rate & 44.81 & 49.03 & 34.68 & 55.29 & 53.51 \\
\hline
\end{tabular}

Table 11. Conversion rate of sewage sludge with water removed.

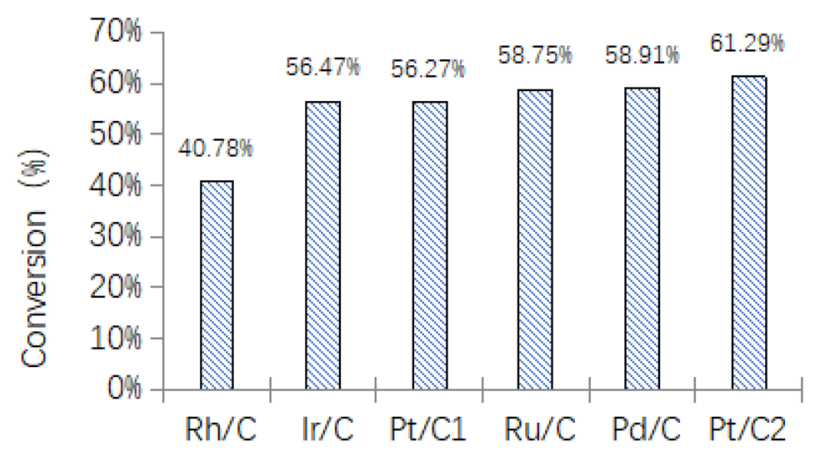

Figure 15. Apparent conversion of sludge.

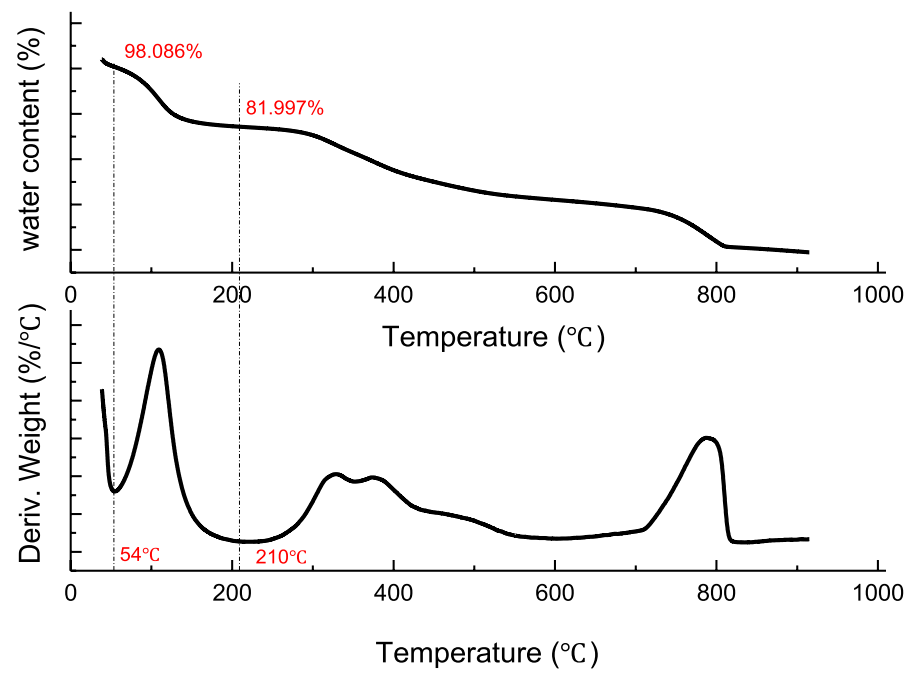

Figure 16. Water content of raw sludge.

the sample from Anshun Green Powered Waste Power Plant. It can be known from Table 11 that after deducting the effect of the chemicals in the sludge, the sludge from Xinzhuang Sewage Treatment Plant has a smaller conversion rate than Table 10. It can be known from Table 10 that after deducting the effects of chemicals and water in municipal sludge, all the sludge conversion rate showed downward trend.

Effect of catalyst to conversion rate:

Firstly, the trend of liquid phase quality under different catalysts was shown in Fig. 14. the weight of liquid phase in the reactor is different, but they were almost between $16 \mathrm{~g} \sim 19 \mathrm{~g}$, which is at the same level.

The trend of sludge conversion rate under different catalyst condition was shown in Fig. 15.

It is known that after the rhodium-carbon catalyst catalyzes sludge, the conversion efficiency of the sludge is only $40.78 \%$, and the conversion rate of others is about $56 \% \sim 62 \%$.

Based on the tga data of Huaxi Sewage Treatment Plant sludge after freeze drying is shown in Fig. 16.

It is known that the moisture content of the original sludge is $98.086 \%-81.997 \%=16.089 \%$. So, we could calculate the theoretical dry matter conversion rate of sewage sludge (Fig. 17), and the actual sludge amount and sludge conversion rate in the experiments are calculated as follows:

Drysludge mass $=$ Original sludge mass $\times(1-$ moisture content $(\%))$ 


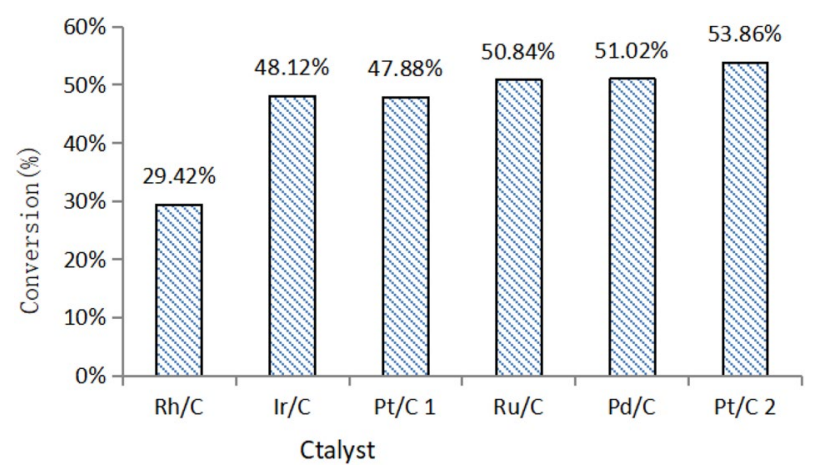

Figure 17. Theoretical dry matter conversion rate of sludge.

\begin{tabular}{|l|l|l|l|l|l|}
\hline Use catalyst & Original sludge $(\mathbf{g})$ & Moisture content (\%) & Dry sludge $(\mathrm{g})$ & Residual sludge $(\mathrm{g})$ & Conversion rate (\%) \\
\hline $\mathrm{Rh} / \mathrm{C}$ & 2.013 & 16.10 & 1.689 & 1.192 & 29.42 \\
\hline $\mathrm{Ir} / \mathrm{C}$ & 2.017 & 16.10 & 1.692 & 0.878 & 48.12 \\
\hline $\mathrm{Pt} / \mathrm{C} 1$ & 2.001 & 16.10 & 1.679 & 0.875 & 47.88 \\
\hline $\mathrm{Ru} / \mathrm{C}$ & 2.056 & 16.10 & 1.725 & 0.848 & 50.84 \\
\hline $\mathrm{Pd} / \mathrm{C}$ & 2.015 & 16.10 & 1.691 & 0.828 & 51.02 \\
\hline $\mathrm{Pt} / \mathrm{C} 2$ & 2.064 & 16.10 & 1.732 & 0.799 & 53.86 \\
\hline
\end{tabular}

Table 12. Sludge conversion rate.

\begin{tabular}{|c|c|c|c|c|c|c|}
\hline Solvent & $\begin{array}{l}\text { Dry sewage sludge mass } \\
\text { (g) }\end{array}$ & Centrifuge tube mass (g) & Catalyst (g) & $\begin{array}{l}\text { Centrifuge tube after } \\
\text { drying + sample mass (g) }\end{array}$ & $\begin{array}{l}\text { Sludge after drying } \\
\text { mass }(\mathrm{g})\end{array}$ & Conversion rate $(\%)$ \\
\hline Isopropanol & 2.056 & 12.827 & 0.100 & 13.785 & 0.858 & 58 \\
\hline Ultra-pure water & 2.003 & 12.960 & 0.100 & 14.915 & 1.855 & 7 \\
\hline Isopropanol + formic acid & 2.076 & 12.915 & 0.100 & 14.510 & 1.495 & 28 \\
\hline Isopropanol + methanol & 2.009 & 12.945 & 0.104 & 13.235 & 0.186 & 91 \\
\hline $\begin{array}{l}\text { Isopropanol + absolute } \\
\text { ethanol }\end{array}$ & 2.003 & 12.900 & 0.101 & 13.935 & 0.934 & 53 \\
\hline
\end{tabular}

Table 13. Conversion rate of sewage sludge.

$$
\text { Conversion rate }=\frac{\text { Dry sludge }- \text { Residual sludge }}{\text { Dry sludge }} \times 100 \%
$$

The results are shown in Table 12 and Fig. 17. Based on the analysis of Table 12 and Fig. 17, we can know that except for the rhodium-carbon catalyt, which only has a conversion rate as low as $29.42 \%$. The others catalysts had a higher conversion rate from 47 to $54 \%$, the catalytic efficiency is almost at the same level, and the catalytic effect is relatively high, indicating that different catalysts have a certain effect on the hydropyrolysis of the sewage sludge.

Effect of solvents to conversion rate:

Effect of solvents to conversion rate were evaluated using the sewage sludge from Huaxi Sewage Treatment Plant, and the conversion rate of sewage sludge were calculated by the formula as follows:

$$
n=\frac{M-(m 1-m 2-m 3)}{M} * 100 \%
$$

$\mathrm{n}$, conversion rate; $\mathrm{m} 1$, total mass after drying g; $\mathrm{m} 2$, centrifuge tube mass g; $\mathrm{m} 3$, catalyst mass g; $\mathrm{M}$, dry sewage sludge mass g.

The results are shown in Table 13.

It can be known from Table 13 that the highest conversion rate of sludge is the reaction of using methanol and isopropanol as solvent, and it as high as $91 \%$, while the lowest is the reaction of using ultrapure water as solvent, and it is only $7 \%$. The reason maybe is because some organic compounds in the sludge are insoluble in water, but soluble in organic solvents. 


\begin{tabular}{|l|l|l|l|l|}
\hline No & $\mathbf{M}_{\mathbf{n}}$ & $\mathbf{M}_{\mathbf{w}}$ & $\mathbf{M}_{\mathbf{z}}$ & $\mathbf{M}_{\mathbf{w}} / \mathbf{M}_{\mathbf{n}}$ \\
\hline Huaxi sewage treatment plant & $1,579,261$ & $2,449,992$ & $4,793,158$ & 1.55 \\
\hline Xinzhuang wastewater treatment plant (phase II) & - & - & - & - \\
\hline Xiaohe sewage treatment plant & 696,288 & $1,140,625$ & $2,460,355$ & 1.64 \\
\hline Anshun green power waste power plant & - & - & - & - \\
\hline
\end{tabular}

Table 14. Sludge liquid product index.

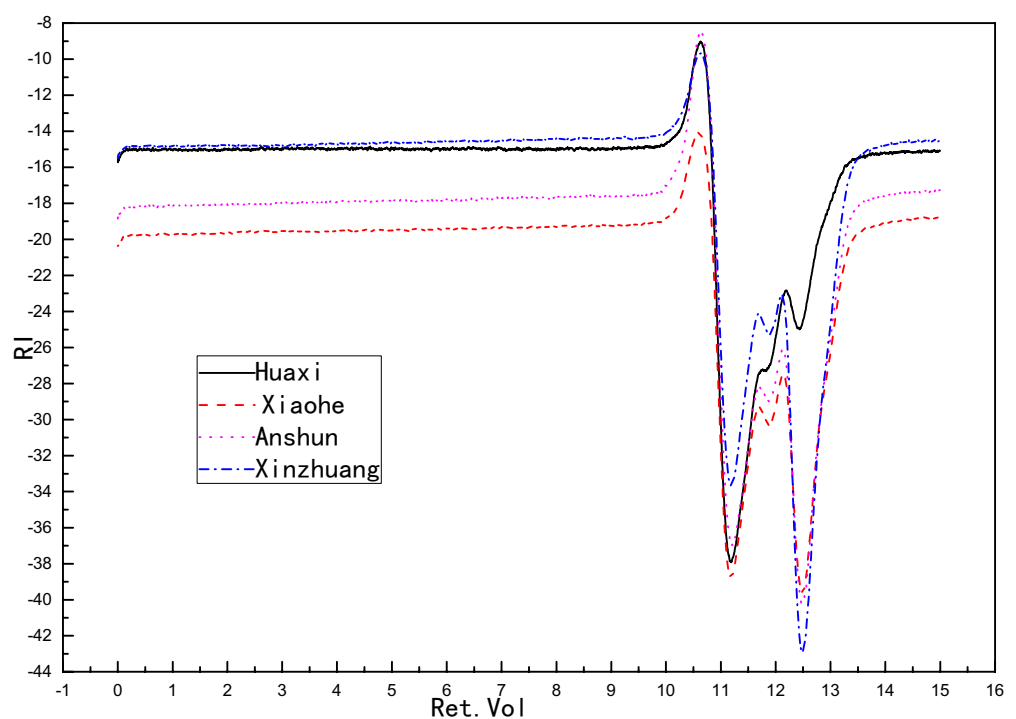

Figure 18. GPC diagram of sludge pyrolysis liquid phase.

Characterization of liquid products. GPC characterization. Effect of sewage sludge source on the molecular weight:

The results were show in Table 14 and Fig. 18, here we only have two samples of different sewage sludge source had the data because some special experimental reason.

Based on the sludge liquid product correlation index table (Table 14), the polymer dispersion coefficient $\mathrm{M}_{\mathrm{w}} /$ $M_{n}$ of Huaxi Sewage Treatment Plant and Xiaohe Sewage Treatment Plant are both greater than 1, indicating that the sludge liquid product is a mixture. The average molecular weight of Xiaohe Sewage Treatment Plant is smaller than that of Huaxi Sewage Treatment Plant and the polymer dispersion coefficient is greater than that.

It can be seen from Fig. 19 that the earlier the peaks, the larger the retention volume. The gpc diagrams of the four sewage treatment plants show similar trends, indicating that the substances contained in each sewage treatment plant are similar.

Effect of catalyst on the molecular weight:

Firstly the mass of liquid phase were calculated as follows: Liquidmassg $=$ Mixture $(g)-d r y$ sludge $(g)$.

After the reaction finished, the liquid phase quality was shown in Table 15.

Liquid substance.

Secondly, gpc analysis was performed to analyze the liquid substance to know the information of its molecular weight and substance distribution. The relative data was shown in Fig. 19 and Table 16.

Based on the analysis of Fig. 19 and Table 16, we could find that all the pdi (pdi: $\frac{M_{w}}{M_{N}}$. (lymer dispersion index) are greater than 1, indicating that the sample components are unevenly distributed and are composed with mixtures; and the liquid products using $\mathrm{Ru} / \mathrm{C}$ and $\mathrm{Rh} / \mathrm{C}$ catalysts have pdi of 1.55 and 1.70 respectively; All of the pdi of the liquid product from $\mathrm{Ir} / \mathrm{C}, \mathrm{Pt} / \mathrm{C} 1, \mathrm{Pd} / \mathrm{C}$ catalyst are close to 2.0 ; while the pdi of the liquid product using $\mathrm{Pt} / \mathrm{C} 2$ catalyst is as high as 2.90 . This shows that the product from $\mathrm{Ru} / \mathrm{C}$ and $\mathrm{Rh} / \mathrm{C}$ catalyst has a smaller molecular weight, followed by the liquid product using $\mathrm{Ir} / \mathrm{C}, \mathrm{Pt} / \mathrm{C} 1, \mathrm{Pd} / \mathrm{C}$ catalyst, and the liquid phase product using the $\mathrm{Pt} / \mathrm{C} 2$ catalyst has the largest molecular weight.

In gpc, the channel pore size of the substance can be large or small. When the polymer flows through the column, the larger molecules are excluded from the small pore size and can only pass through the large pore size. Short time; small molecules pass through small pores, the rate of passage is slower, and the time to be regretted is longer. Medium-sized molecules are based on large molecules and small molecules. Therefore, in the gpc analysis, if more peaks appear at early part, the molecular weight of the substance is larger. Figure 19 is the retention volume-difference graph, which shows that there is a difference in peak intensity among the samples, but the peak positions are almost same, indicating that there is a selective difference between the catalysts. But the product types are almost same. 


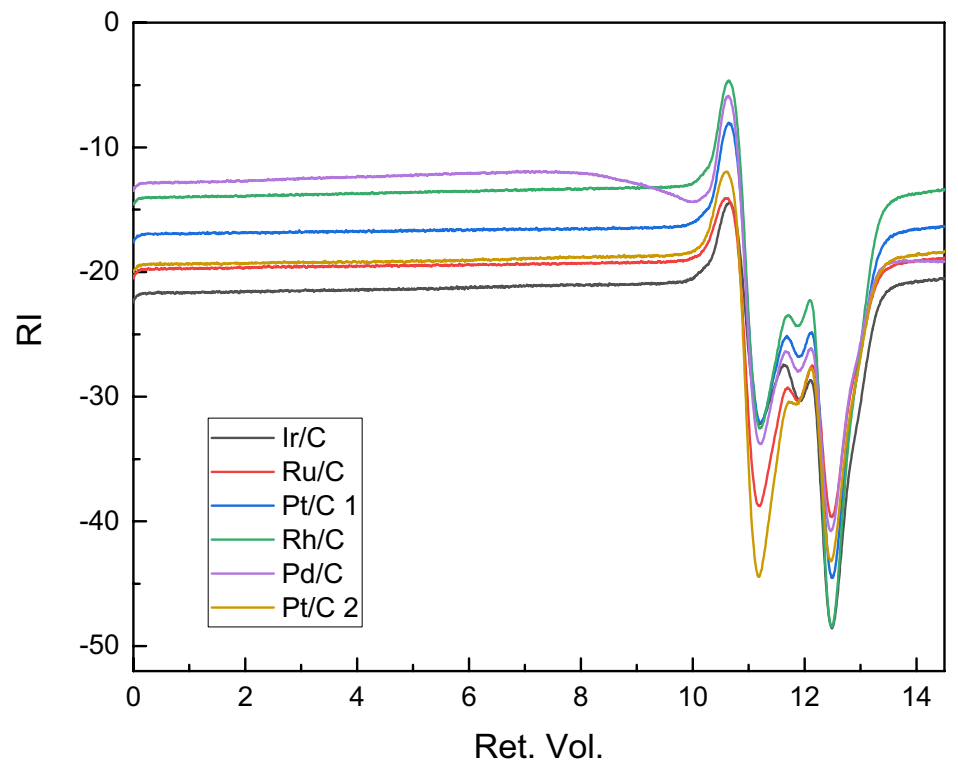

Figure 19. gpc spectra of liquid products under different catalyst conditions.

\begin{tabular}{|l|l|l|l|}
\hline Catalyst & Mixture $(\mathrm{g})$ & Dry sludge $(\mathrm{g})$ & Liquid phase mass $(\mathrm{g})$ \\
\hline $\mathrm{Rh} / \mathrm{C}$ & 18.527 & 1.292 & 17.235 \\
\hline $\mathrm{Ir} / \mathrm{C}$ & 17.935 & 0.992 & 16.943 \\
\hline $\mathrm{Pt} / \mathrm{C} 1$ & 18.404 & 0.981 & 17.423 \\
\hline $\mathrm{Ru} / \mathrm{C}$ & 18.596 & 0.958 & 17.638 \\
\hline $\mathrm{Pd} / \mathrm{C}$ & 17.855 & 0.928 & 16.927 \\
\hline $\mathrm{Pt} / \mathrm{C} 2$ & 18.976 & 0.899 & 18.077 \\
\hline
\end{tabular}

Table 15. Liquid product quality.

\begin{tabular}{|l|c|l|l|l|}
\hline Catalyst & \multicolumn{1}{|l|}{$\mathbf{M n}$} & $\mathbf{M w}$ & $\mathbf{M z}$ & $\mathbf{M w} / \mathbf{M n}$ \\
\hline $\mathrm{Ir} / \mathrm{C}$ & 627,288 & $1,303,814$ & $5,856,110$ & 2.08 \\
\hline $\mathrm{Ru} / \mathrm{C}$ & $1,579,261$ & $2,449,992$ & $4,793,158$ & 1.55 \\
\hline $\mathrm{Pt} / \mathrm{C} 1$ & 353,790 & 723,524 & $6,923,026$ & 2.06 \\
\hline $\mathrm{Rh} / \mathrm{C}$ & 423,862 & 721,300 & $2,257,133$ & 1.70 \\
\hline $\mathrm{Pd} / \mathrm{C}$ & 673,566 & $1,367,729$ & $8,113,982$ & 2.03 \\
\hline $\mathrm{Pt} / \mathrm{C} 2$ & $2,569,692$ & $7,441,605$ & $22,278,798$ & 2.90 \\
\hline
\end{tabular}

Table 16. Molecular weight of liquid product and their pdi.

Effect of solvent on the molecular weight:

Effect of solvent on the molecular weight were shown in Fig. 20 and the Table 17. The liquid obtained after the catalytic cracking experiments of sludge by adding different solvents showed its position of large peaks appeared at almost same time. Their differences only could be found at a small part area. It means that the types of small molecules obtained after adding different solvents to the catalytic cracking reaction are almost the same.

However, PDI represents the dispersion coefficient of the polymer. When the pdi value is greater than 1 , it indicates that the peak is wider and the substance is a mixture. The closer the pdi value is to 1 , the narrower the peak is. When pdi is equal to 1 , it is an absolute monodispersion. It can be known that when the experimental solvent is isopropanol, isopropanol plus formic acid, isopropanol plus anhydrous ethanol, the product in the reaction liquid phase is a mixture, and when ultrapure water and isopropanol plus methanol are used as solvents due to limition of analysis conditions, we did not get valid data. But we can see that the PDI data is changed from 1.27 to 3.08 , which means that solvent has a strong effect on the molecular weight of liquid products. 


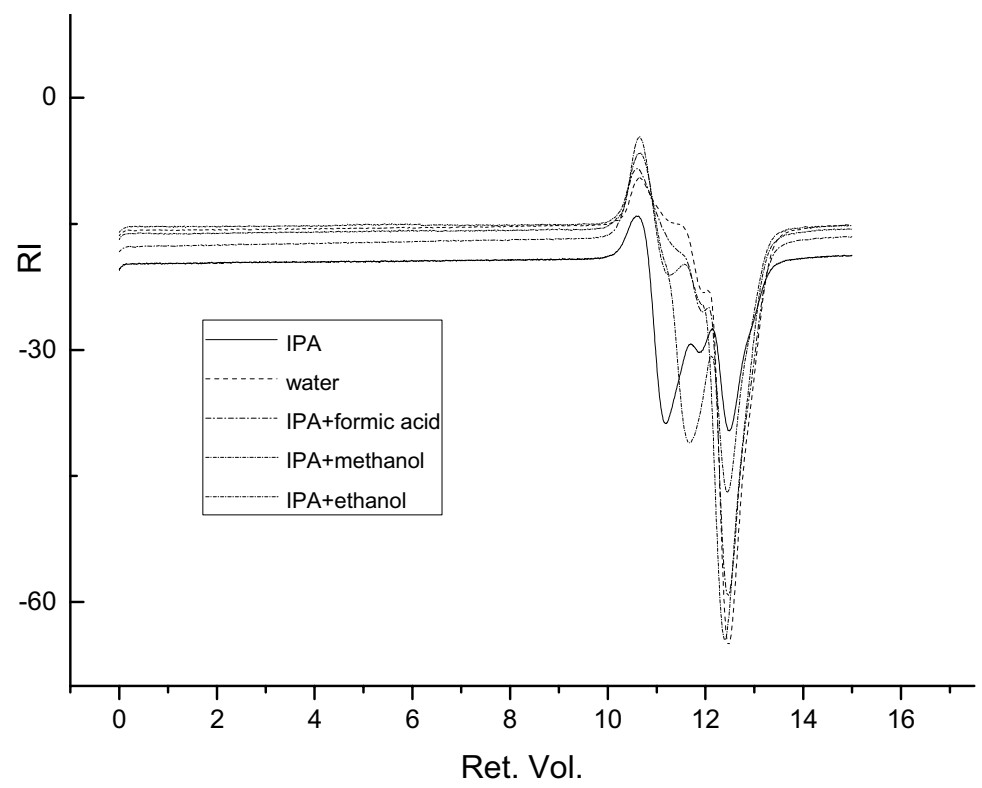

Figure 20. Liquid phase gpc diagram.

\begin{tabular}{|l|l|l|l|l|l|}
\hline Solvent & $\mathbf{M n}$ & $\mathbf{M w}$ & $\mathbf{M z}$ & $\mathbf{M p}$ & PDI \\
\hline Isopropanol & $1,579,261$ & $2,449,992$ & $4,793,158$ & $1,171,446$ & 1.55 \\
\hline Ultra-pure water & - & - & - & - & - \\
\hline Isopropanol + formic acid & 164,611 & 506,878 & $6,607,182$ & 171,611 & 3.08 \\
\hline Isopropanol + methanol & - & - & - & - & - \\
\hline Isopropanol + absolute ethanol & $1,273,263$ & $1,611,583$ & $2,824,465$ & 980,100 & 1.27 \\
\hline
\end{tabular}

Table 17. GPC experimental data.

GC-MS characterization. The data submitted for inspection are processed by Amdis and compared to Nist2 database to obtain the substances in the liquid products (Fig. 21): The main components of the liquid phase products are alkane, olefin, ketones, aldehydes, phenols, ethers, esters, and some nitrogen-containing compounds (pyridine, aniline) and other organic components. Based on this analysis, we can conclude that it is feasible to produce valuable small molecular substances by catalytic pyrolysis of sewage sludge.

Based on the analysis of the gc-ms spectrum, the liquid products mainly contain the following products (Table 18):

As a conclusion of these analyses, alkane, olefin, aromatic compound ketones, aldehydes, phenols, ethers, esters, and some nitrogen-containing compounds (pyridine, aniline) and other organic components were the main components of the liquid product. These results also showed that valuable small molecular chemicals could be produced from catalytic pyrolysis of sewage sludge.

These chemical classes were detected again by GCxGC (Fig. 22), which is a new technique to analyze organic compound classes present in bio-oil because they will be shown in special regions in the GCxGC figures. Results from GC-MS and GCxGC were the same.

IPA is active under reaction conditions because we had found there were gas phase components formation in the blank reaction (only IPA and catalyst, Figs. 23, 24). Acetone, methylsiobutylketone (MIBK), 2-hexanol, and 2,6-dimethyl-4-heptanone were observed in the liquid phase.

It is possible that ketones and alcohols were produced from IPA (Scheme 1). The process included dehydrogenation of IPA to acetone, aldol condensation to diacetylacetone (DA), mestityleoxide (MO) formed from DA, and finally catalytically hydrogenated to MIBK. Under the reaction conditions with Pt, ketones could be hydrogenated to produce the related alcohols. These reactivities of IPA had been reported by Kleinert et al. 18 and Kloekhorst et al. 32 .

Effect of catalyst on the liquid substances:

Gc-ms analysis was performed on all liquid product from different catalyst, and the relevant data analysis is shown in Figs. 25, 26 and Fig. S4 to Fig. S8 in the supporting information.

It is known from Fig. 27 that the liquid phase products using $\mathrm{Ir} / \mathrm{C}, \mathrm{Ru} / \mathrm{C}, \mathrm{Pd} / \mathrm{C}$, and $\mathrm{Pt} / \mathrm{C} 2$ catalysts, the peak trends of the substances are almost the same (group a), while peaks from $\mathrm{Pt} / \mathrm{C} 1$ and rhodium/C were almost similar (group b), and group b has more peaks than group a, and the peak height and peak area are bigger than 


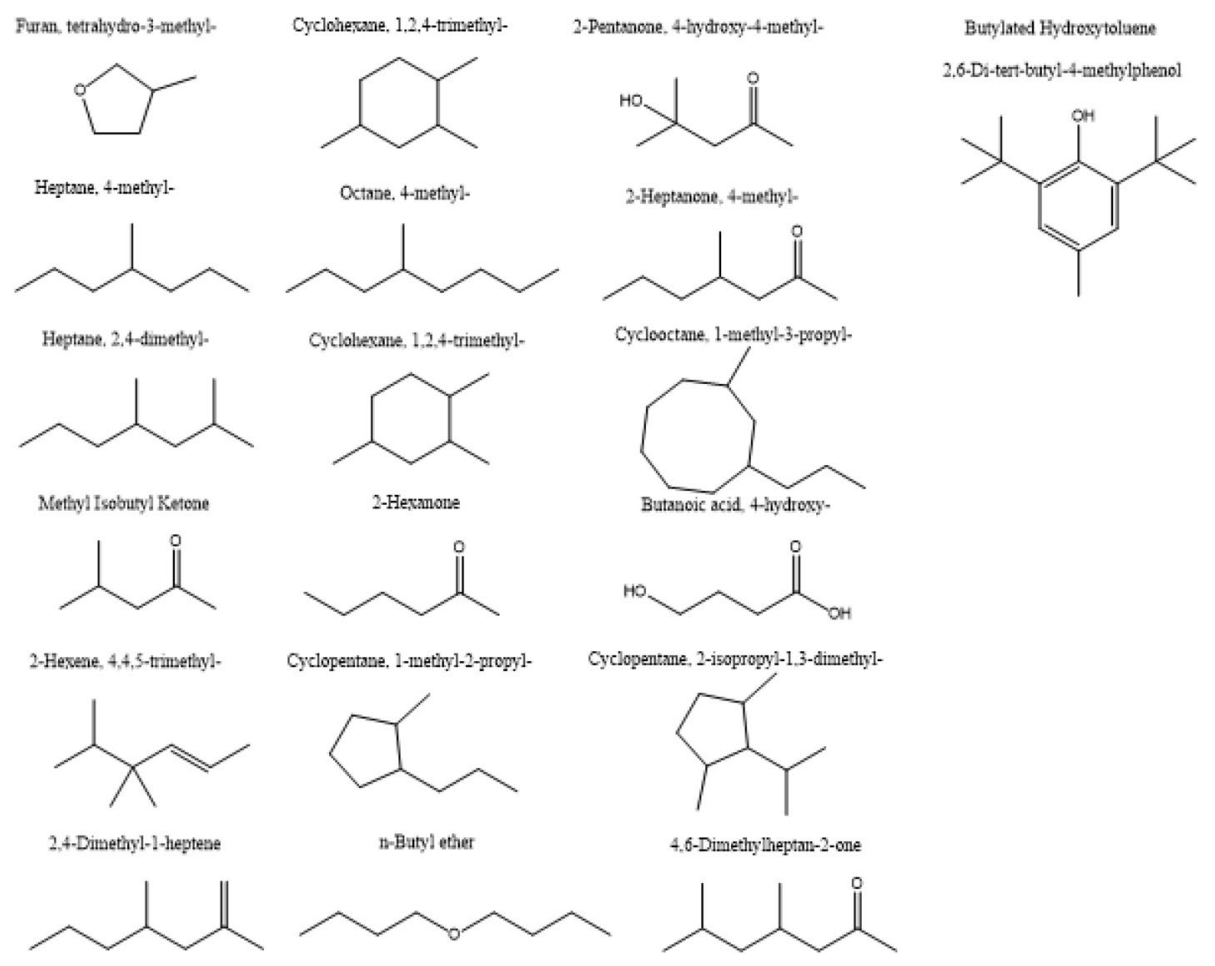

Figure 21. Main substances in the liquid products of sewage sludge catalytic cracked.

group a. These results showed that under the same conditions, the liquid phase products of $\mathrm{Pt} / \mathrm{C} 1, \mathrm{Rh} / \mathrm{C}$ had more contents and product types than the liquid phase products from $\mathrm{Ir} / \mathrm{C}, \mathrm{Ru} / \mathrm{C}, \mathrm{Pd} / \mathrm{C}, \mathrm{Pt} / \mathrm{C} 2$.

Effect of solvent on the liquid substances:

The liquid products from differerent solvents were analyzed by gc-ms and the results were shown below:

1. Some small molecules in the liquid phase from isopropanol as solvent are:

Formaldehyde n-butyl formate; 2,4,6-trimethylpyridine; 2,4-di-1,1-dimethylethylphenol; 3,5-cyclohexadiene1,2-dione- 3,5-Di-1,1-dimethylethyl; 1-bromoethyl-4fluorobenzene; 2,2-dimethyl-3-hexanone; malonamide; 2- (2-hydroxyethyl (Oxy) ethyl-octadecanoic acid; trimethylamine oxide; trimethylisopyrazine; 3,5-dimethylcyclohexanone; 2,3-dimethyl-1,4-pentene-2-Alcohol; 1,2-dimethylcyclohexane; 1,3-butadiene-1-carboxylic acid; thienyl chloride; 2-acetyl-1-phenylhydrazine; 1,1,1-trinitroethane ; 1,3,5-triazine-2,4,6-triamine; 2 (3 h) -furanone, dihydro-5-methyl; n-ethane-nn-dimethyl-n- Nitrosourea; 2,4-di-1-methylethyl-phenol.

2. Some small molecules in the liquid phase from ultrapure water as solvent are:

Bromoethyl mercury; 1-acetaldehyde-2,3,6-trichlorobenzene; 1-n-butylamine-n-butadiene; hexene; methyl succinic anhydride; 2-methyl-propanal; Chloro-acetic acid; 1,1-ethylene-di-oxy-di-propane; isopropanol; dextroamphetamine; butyl mesylate.

3. Some small molecules in the liquid phase from isopropanol and formic acid as solvents are:

Acetone; n-pentane; pyroglutamic acid; 3-methyl-pentane; 3-butyn-2-ol; hexene; methyl 2-butyrate; dl3-methylcyclopentanone; methyl Cyclohexane; cycloheptane; dl-camphorquinone; dimethyl phosphite; 2-aminopyridone; 2-acetyl-5-methylfuran; 1,2-dimethyl-cyclohexane; 1,5-Dimethyl-2-pyrrolidone.

4. Some small molecules in the liquid phase from isopropanol and methanol as solvents are:

D-amphetamine; benzoylmethylsulfonyl chloride; $\mathrm{n}$ - (2-methoxyphenyl) -3-oxo-butyramide.

5. Some small molecules in the liquid phase from isopropanol and ethanol as solvents are:

1,1-ethylidene diphosphine-di-oxy-propane; alkylbenzene; cycloheptane; 2,5-dimethylfuran; 2,5-dihydropyrrole; methyl caprylic acid; DL-camphorquinone; 3 , 4-dimethyl-2-hexanone; pyrrolidine; n-pentanol; 2,2-diethoxypropane; 1,2-dimethyl-cyclohexane; vinyl-ethylene oxide; $2(1 \mathrm{H})$-pyridone; 2-ethoxy-ethanol; 1,4-cyclohexanedione; butyric acid; 2-ethane-2-butenal; 6-hydroxy-2 (1 h) pyridone; Methyl bromide; 3,5-dimethylcyclohexanone.

We can conclude that solvent has a strong effect on the liquid products if the others conditions are same, so solvent should be taken in account if more researches will be performed in this research aerea.

Characterization of gas products. Effect of source of sewage sludge to gas products. The terminal pressures of sludge pyrolysis reactions from different sewage sludge source were shown Table 19:

It is known that the terminal pressure is almost same in all reactions at same conditions, which meant that the total amount of gas products might be almost same although their compositions might be different.

External standard quantitative analysis method was applyied to the gas-gc measurement of gas product from the pyrosis of sewage sludge, and the calculation formula is: 


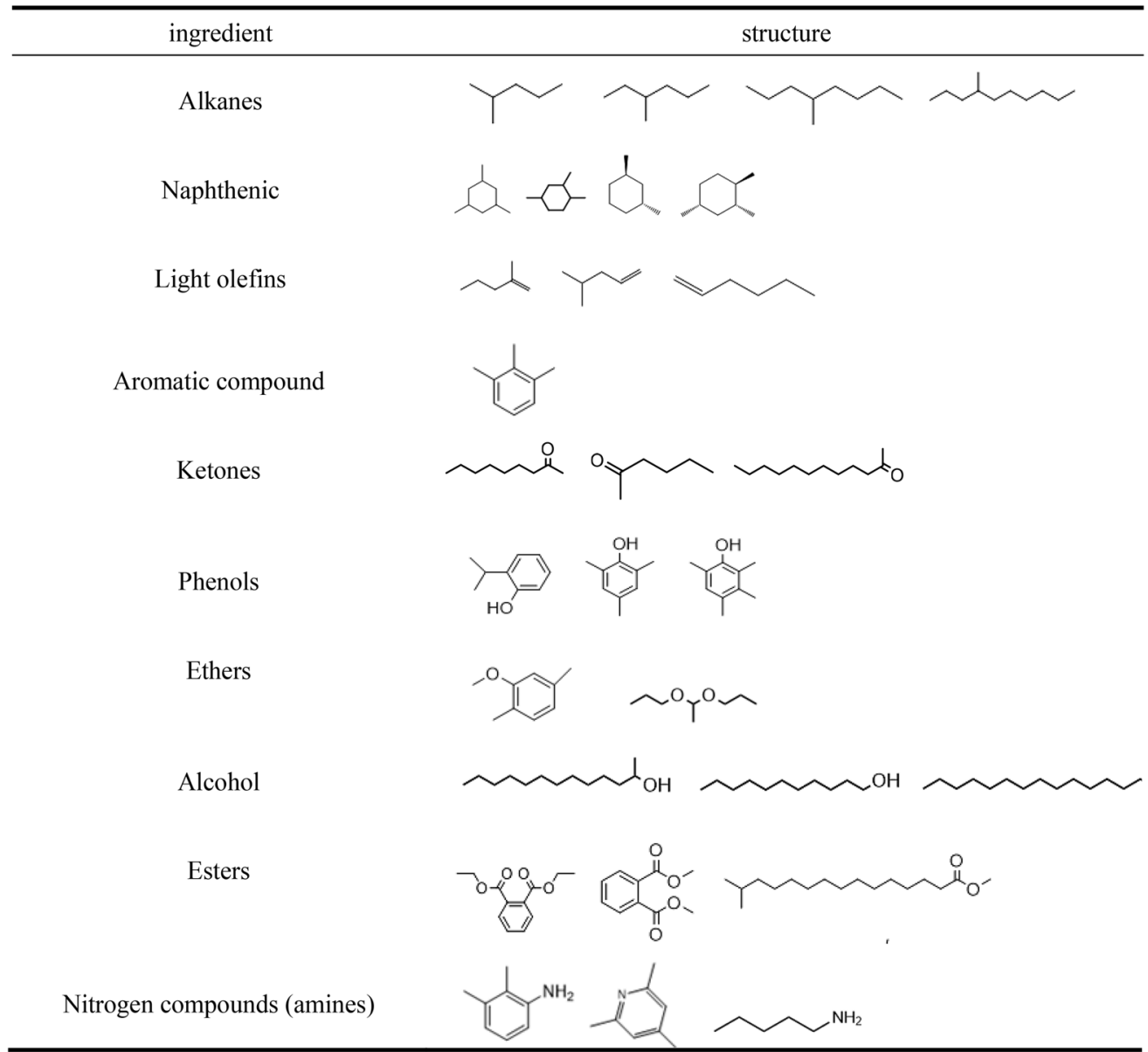

Table 18. Main components of liquid products.

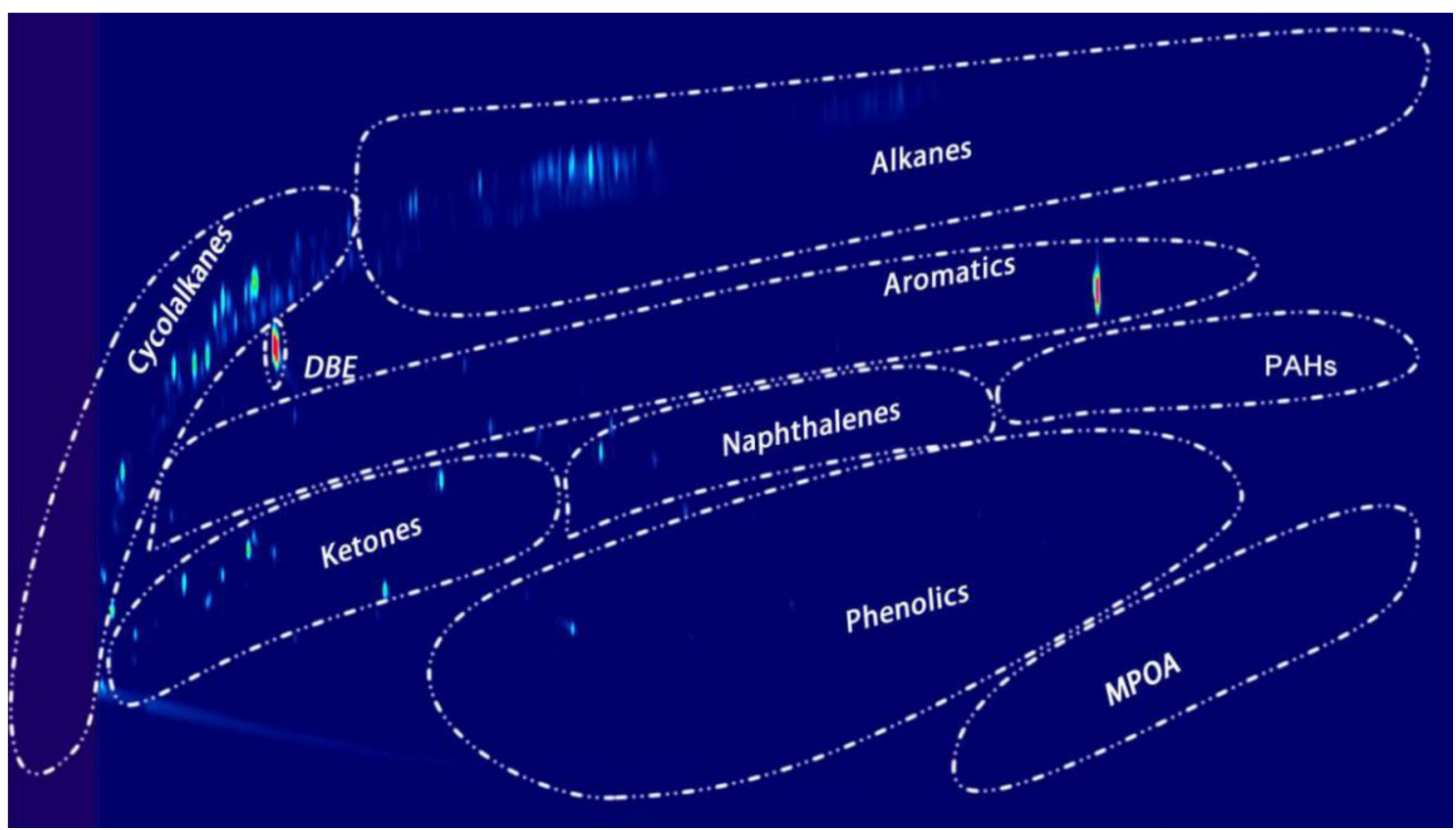

Figure 22. Liquid product analysis with GC-GC (reaction was performed with $\mathrm{Pt} / \mathrm{C}$ as the catalyst, the reaction temperature was set at $400^{\circ} \mathrm{C}$, and reaction time was $7 \mathrm{~h}$ ). DBE was the internal standard for GC analysis. 


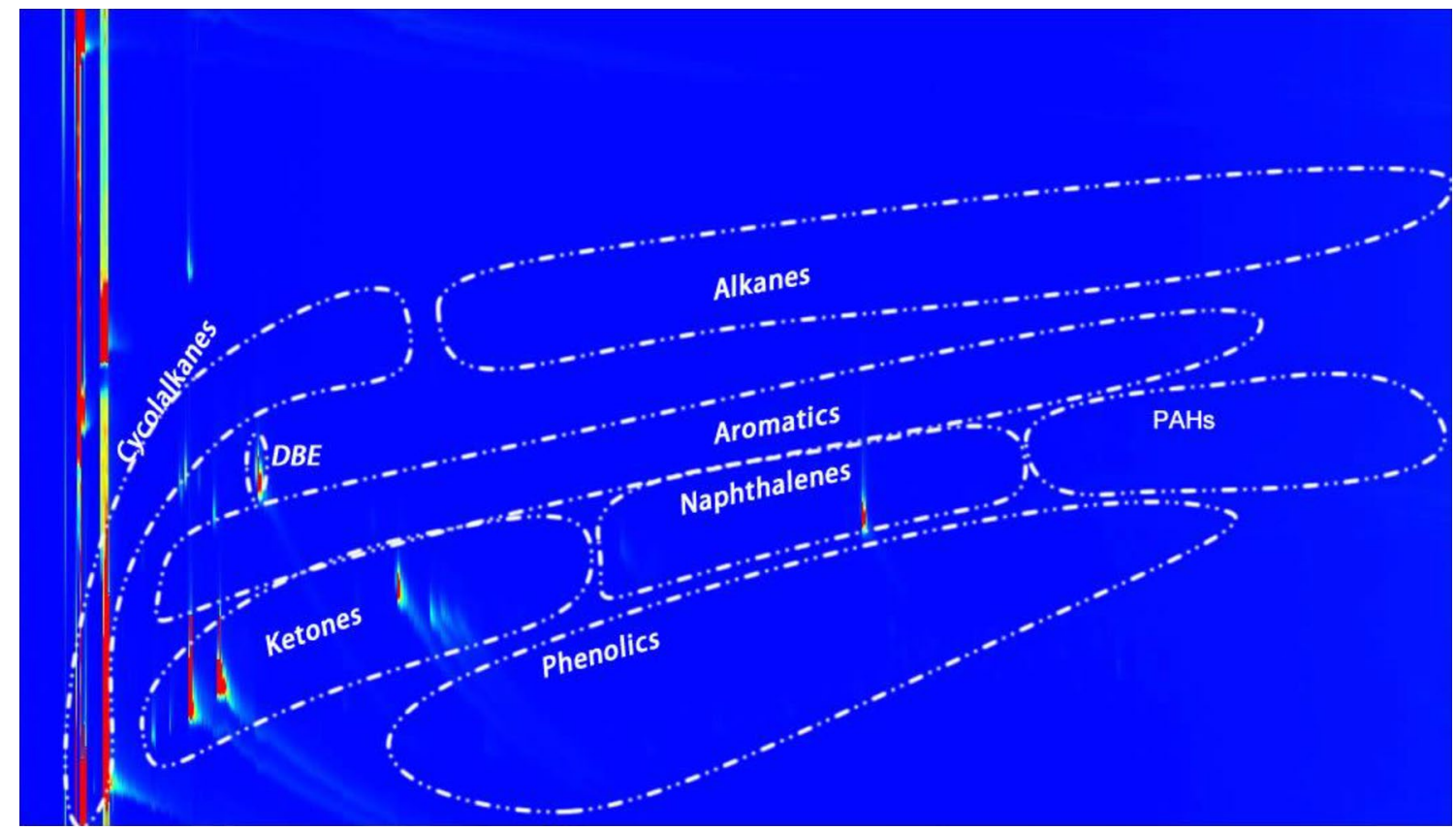

Figure 23. GCxGC plot of the liquid phase of a blank reaction.

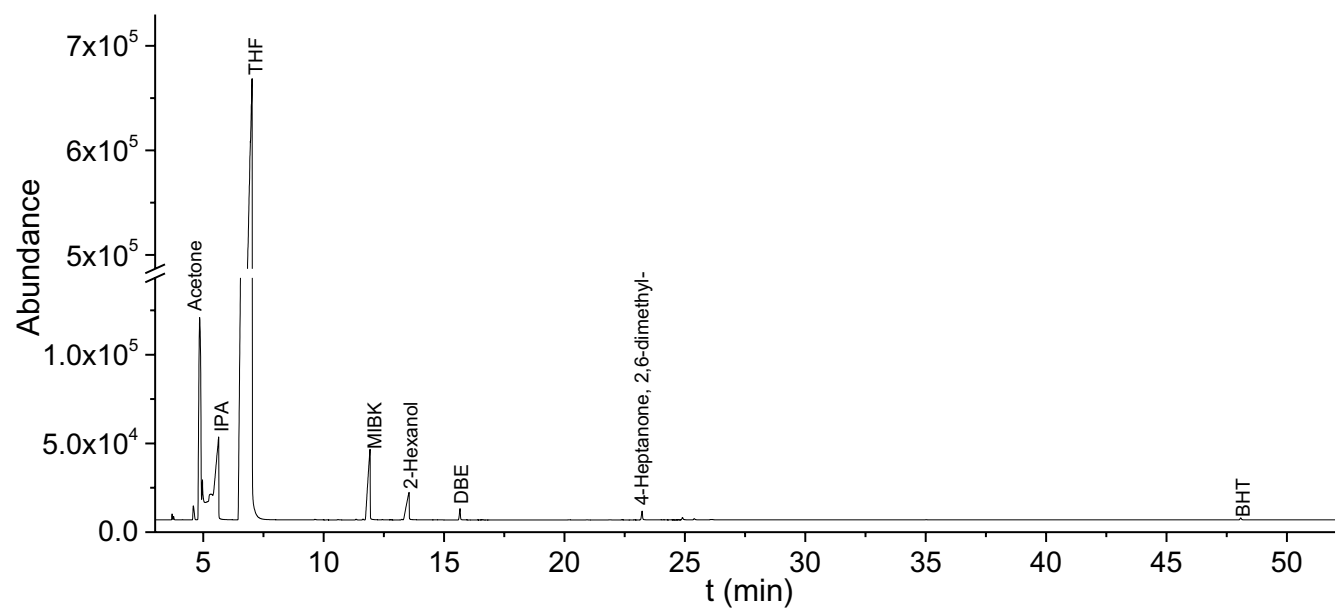

Figure 24. GC-MS-FID results of blank reaction (Pt on carbon as the catalyst, reaction temperature is $400{ }^{\circ} \mathrm{C}$ and time was $7 \mathrm{~h}$ with THF as the solvent, DBE is used as the internal standard for the analysis and BHT is the stabilizer of THF).

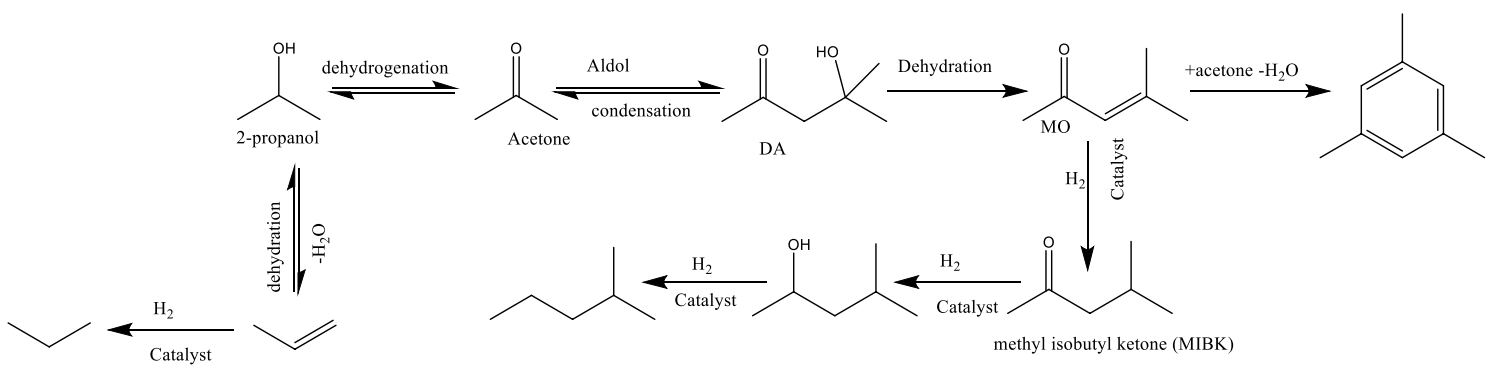

Scheme 1.. Possible reaction pathway for IPA $\left(400{ }^{\circ} \mathrm{C}, \mathrm{Pt} / \mathrm{C}\right)$. 
$\mathrm{Pt} / \mathrm{C} 1$

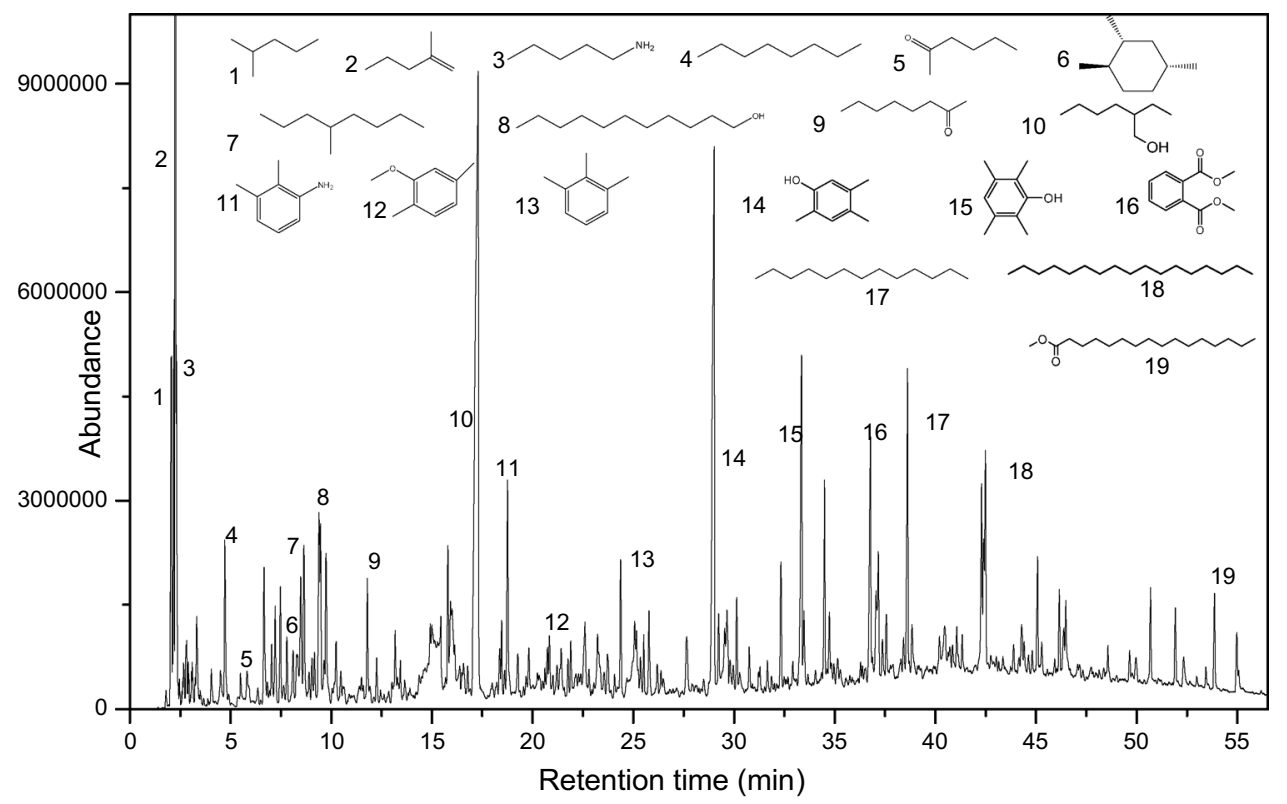

Figure 25. gc-ms analysis of liquid product using Pt/C 1.

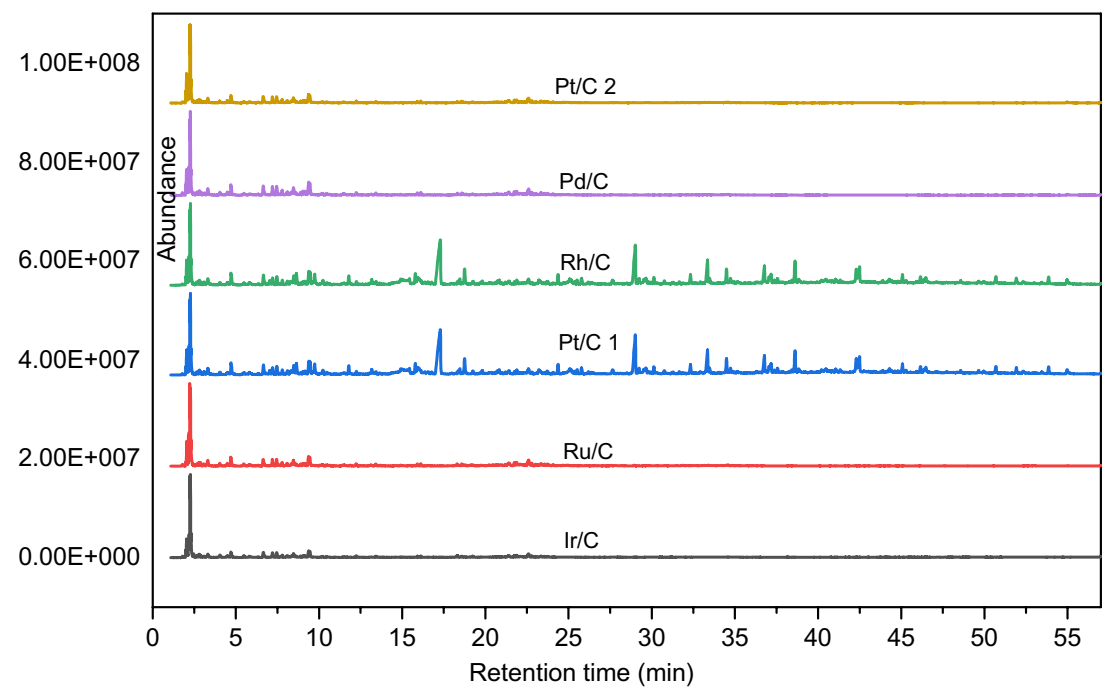

Figure 26. Gc-ms peaks of liquid products with different catalysts.

$$
C_{i}=\frac{C_{s, i}}{A_{s, i}} * A_{i}
$$

where $C_{i}$, in the sample $i$ content of components; $C_{s, i}$, in the standard sample $i$ content of components; $A_{s, i}$, in the standard sample $i$ peak area of the component; $A_{i}$, in the sample $i$ peak area of the component;

The related data of standard gas are shown in the Table 20.

The gas product results of sludge pyrolysis obtained by calculation are shown in Table 21 .

The gas composition analysis results of sludge pyrolysis from different sources also were shown in Fig. 27.

The following conclusions could be obtained from Fig. 27 and Table 20:

1. The yields of methane and carbon dioxide in the catalytic hydropyrolysis gas of sewage sludge from different sewage treatment plants are the least.

2. Carbon monoxide keeps the largest amount in all sources except for the Xinzhuang Wastewater Treatment Plant (Phase II). According to the FTIR data analysis of sludge from various sewage treatment plants, it can 


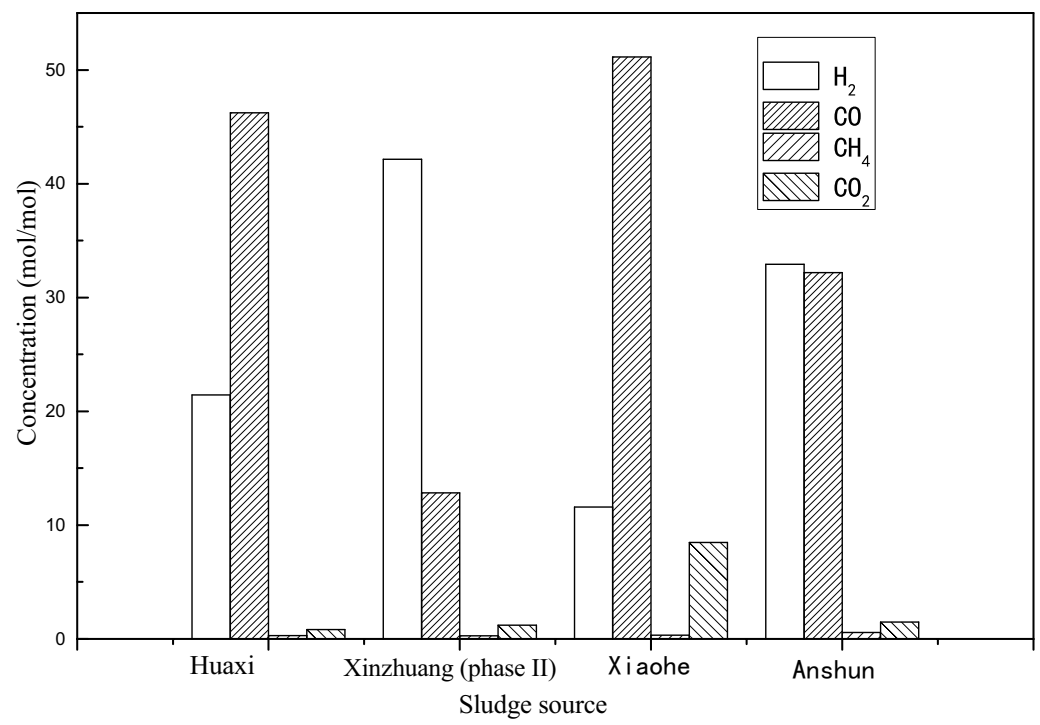

Figure 27. Gas phase composition and concentration diagram of sludge pyrolysis.

\begin{tabular}{|l|l|l|l|l|}
\hline $\begin{array}{l}\text { Huaxi sewage treatment plant } \\
(\mathbf{M P a})\end{array}$ & $\begin{array}{l}\text { Xinzhuang wastewater treatment } \\
\text { plant (phase 1) (MPa) }\end{array}$ & $\begin{array}{l}\text { Xinzhuang wastewater treatment } \\
\text { plant (phase II) (MPa) }\end{array}$ & $\begin{array}{l}\text { Xiaohe sewage treatment plant } \\
\text { (MPa) }\end{array}$ & $\begin{array}{l}\text { Anshun green power renewable } \\
\text { energy Co }(\mathbf{M P a})\end{array}$ \\
\hline 1.9 & 1.7 & 1.8 & 2.0 & 2.0 \\
\hline
\end{tabular}

Table 19. Terminal pressure of sludge pyrolysis reaction.

\begin{tabular}{|l|l|l|}
\hline Component & Content (mol/mol) (\%) & Peak time (5 min/group) \\
\hline $\mathrm{H}_{2}$ & 15.0 & $0.3-0.5 \mathrm{~min}$ \\
\hline $\mathrm{CO}$ & 6.01 & $0.7-0.9 \mathrm{~min}$ \\
\hline $\mathrm{CH}_{4}$ & 4.00 & $1.9-2.2 \mathrm{~min}$ \\
\hline $\mathrm{CO}_{2}$ & 5.02 & $3.0-3.6 \mathrm{~min}$ \\
\hline $\mathrm{Ar}$ & 69.97 & - \\
\hline
\end{tabular}

Table 20. Standard gas peaks.

\begin{tabular}{|l|l|l|l|l|l|}
\hline Gas type (mol/mol) & $\mathbf{H}_{2}$ & $\mathbf{C O}$ & $\mathbf{C H}_{4}$ & $\mathbf{C O}_{2}$ & Total concentration \\
\hline Huaxi sewage treatment plant & 21.44 & 46.24 & 0.29 & 0.82 & 68.79 \\
\hline Xinzhuang wastewater treatment plant (phase 1) & - & - & - & - & - \\
\hline Xinzhuang wastewater treatment plant (phase II) & 42.15 & 12.83 & 0.28 & 1.20 & 56.46 \\
\hline Xiaohe sewage treatment plant & 11.58 & 51.15 & 0.31 & 8.47 & 71.51 \\
\hline Anshun green power waste power plant & 32.92 & 32.20 & 0.57 & 1.48 & 67.17 \\
\hline
\end{tabular}

Table 21. Summary of gas product distribution from pyrolysis of sewage sludge.

be inferred that carbon monoxide comes from the carbonyl groups, primary fatty alcohols and secondary fatty alcohols in the sewage sludge.

3. The amount of carbon monoxide produced by the dewatered sludge in the Xiaohe Sewage Treatment Plant is much larger than the sludge samples of the other 3 sewage treatment plants under the same experimental conditions. Polyacrylamide, which contains carbonyl groups, will increase output.

4. Due to the limitation of instrument detection technology, only five gases, including hydrogen, carbon dioxide, carbon monoxide, methane and argon had be detected.

5. After the pyrolysis of sludge from different sewage treatment plants, more carbon monoxide gas is generated because carbon monoxide is the basic raw material for the production of carbonyl chemicals ${ }^{103}$. Therefore, carbon monoxide in the sludge pyrolysis gas can be separated as a resource choice of sludge pyrolysis gas. 


\begin{tabular}{|l|l|}
\hline Catalyst & Pressure $\mathbf{( M P a )}$ \\
\hline $\mathrm{Ir} / \mathrm{C}$ & 1.9 \\
\hline $\mathrm{Ru} / \mathrm{C}$ & 1.9 \\
\hline $\mathrm{Pt} / \mathrm{C} 1$ & 1.9 \\
\hline $\mathrm{Rh} / \mathrm{C}$ & 1.7 \\
\hline $\mathrm{Pd} / \mathrm{C}$ & 1.9 \\
\hline $\mathrm{Pt} / \mathrm{C} 2$ & 1.7 \\
\hline
\end{tabular}

Table 22. Pressure at the end of the experiment.

\begin{tabular}{|l|c|l|l|l|l|l|}
\hline Catalyst & $\mathbf{c ~} \mathbf{H}_{\mathbf{2}}(\%)$ & $\mathbf{c ~} \mathbf{C O}(\%)$ & $\mathbf{c ~ C H}_{4}(\%)$ & $\mathbf{c ~ C O}_{2}(\%)$ & Total concentration & $\mathbf{H}_{2} / \mathbf{C O}$ \\
\hline $\mathrm{Ir} / \mathrm{C}$ & 7.57 & 62.14 & 0.21 & 0.87 & 70.79 & 8.21 \\
\hline $\mathrm{Ru} / \mathrm{C}$ & 19.59 & 49.02 & 0.27 & 0.87 & 69.75 & 2.50 \\
\hline $\mathrm{Pt} / \mathrm{C} 1$ & 9.49 & 54.35 & 0.26 & 0.79 & 64.88 & 5.73 \\
\hline $\mathrm{Rh} / \mathrm{C}$ & 29.51 & 25.00 & 0.45 & 1.10 & 56.06 & 0.85 \\
\hline $\mathrm{Pd} / \mathrm{C}$ & 46.94 & 10.35 & 0.45 & 1.15 & 58.88 & 0.22 \\
\hline $\mathrm{Pt} / \mathrm{C} 2$ & 53.76 & 10.95 & 0.45 & 1.01 & 66.17 & 0.20 \\
\hline
\end{tabular}

Table 23. Components and contents of gas-phase products.

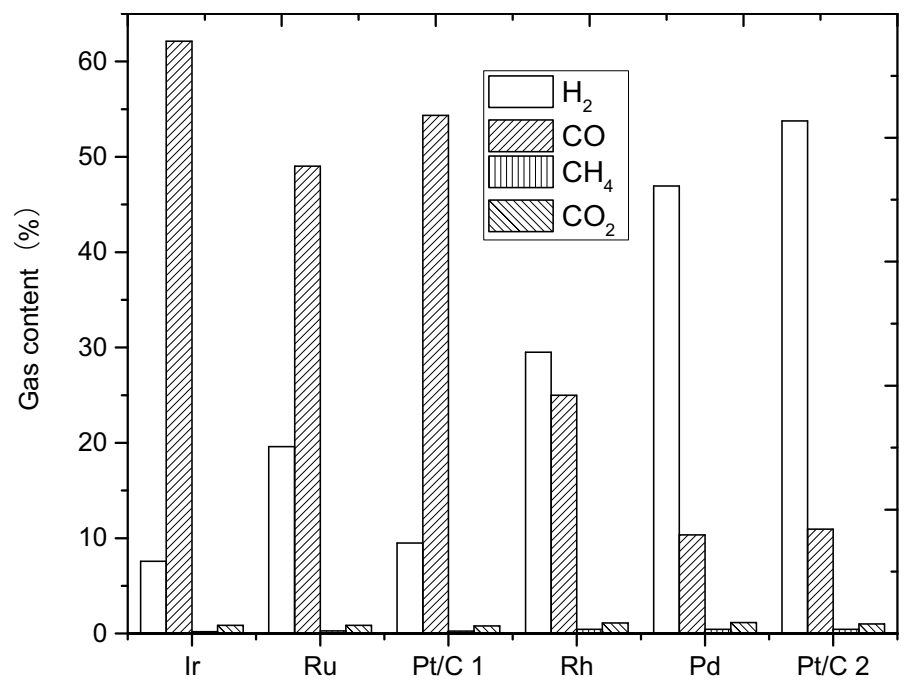

Figure 28. Composition and content of gas phase products.

6. The sludge pyrolysis gas contains hydrogen, which may come from the preparation of the reaction system, or it may come from the cracking of sludge and isopropanol, so it should be distinguished whether the hydrogen comes from the sludge pyrolysis.

Effect of catalyst to gas products. The terminal pressures of sludge pyrolysis reactions from different sewage sludge source were shown Table 22:

It is known that the terminal pressure is almost same in all reactions at same conditions, which meant that the total amount of gas products might be almost same although their compositions might be different.

The calculation and analysis methods were same to the former part, and here the content of the gas products was shown. The results are shown in Table 23.

The comparison of the percentage change of the concentration of each component also was shown in Fig. 28.

Based on these analysis, we can see that the partial pressures of $\mathrm{H}_{2}$ in the gas phase products from $\mathrm{Ir} / \mathrm{C}$, $\mathrm{Ru} / \mathrm{C}, \mathrm{Pt} / \mathrm{C}$ 1, Rh/C, Pd/C, and Pt/C 2 are $0.144 \mathrm{MPa}, 0.372 \mathrm{MPa}, 0.180 \mathrm{MPa}, 0.502 \mathrm{MPa}, 0.892 \mathrm{MPa}, 0.94 \mathrm{MPa}$, respectively. It is known that the pressure of hydrogen is lower than $1 \mathrm{MPa}$, which is the start hydrogen pressure, indicating that hydrogen may not be the experimental product. This conclusion also could be proved from the fact that the order of hydrogenation capacity of these catalysts is: $\mathrm{Ir} / \mathrm{C}>\mathrm{Pt} / \mathrm{C} 1>\mathrm{Ru} / \mathrm{C}>\mathrm{Rh} / \mathrm{C}>\mathrm{Pd} / \mathrm{C}>\mathrm{Pt} / \mathrm{C} 2$. 


\begin{tabular}{|l|l|r|l|l|}
\hline Solvent & $\mathbf{H}_{2}$ & \multicolumn{1}{l|}{$\mathbf{C O}$} & $\mathbf{C H}_{4}$ & $\mathbf{C O}_{2}$ \\
\hline Isopropanol & 15.89 & 54.59 & 0.24 & 0.96 \\
\hline Ultra-pure water & 37.50 & 8.28 & 4.70 & 2.73 \\
\hline Isopropanol + formic acid & 55.43 & 12.45 & 0.31 & 3.70 \\
\hline Isopropanol + methanol & 28.68 & 40.27 & 0.83 & 0.83 \\
\hline Isopropanol + absolute ethanol & 41.29 & 9.43 & 0.33 & 2.38 \\
\hline
\end{tabular}

Table 24. Summary of gas product concentration from different solvents(unit: $\mathrm{mol} / \mathrm{mol}$ ).

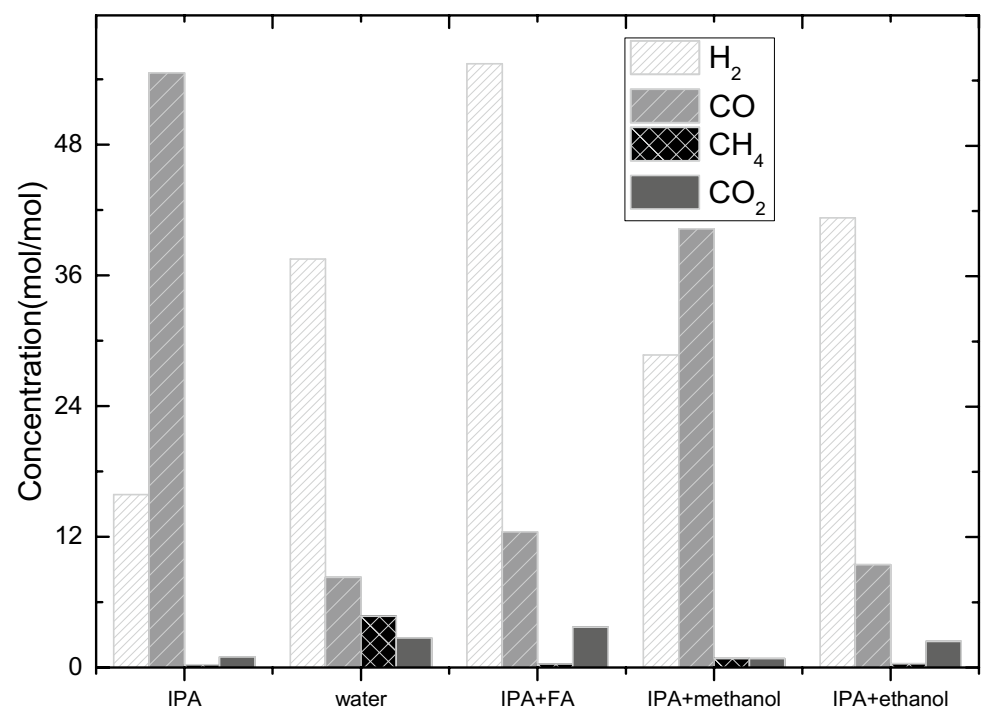

Figure 29. Composition of different components in the gas product.

Effect of solvents to gas products. The calculation and analysis methods were same to the former part, and here the mole fraction of the gas products was used. The results are shown in Table 24.

The results also were shown in Fig. 29.

It can be known from Table 24 that for isopropanol as the solvent, the hydrogen and methane are the least compared to the other four solvents, only $15.89 \%$ and $0.24 \%$, but the carbon monoxide $(54.59 \%)$ is the most. This is because Isopropanol contains three carbon atoms. Compared with other solvents, carbon dioxide has the most carbon atoms. Under high temperature conditions, carbon and water react to form carbon monoxide and hydrogen. When isopropanol was used, the solvent did not contain water, and the moisture is small, so the amount of hydrogen produced is small.

As can be seen from Table 24, methane (4.70\%) produced more when ultrapure water was used as the solvent, because water molecules are polar molecules, and more hydrogen ions are dissociated than other solvents. The carbon atoms in methane are derived from the decomposition of organic matter in the sludge. There may be carbon-carbon double bond breaks and carbon-carbon single bond breaks. Methane requires four hydrogen ions, so more hydrogen ions are generated for dissociation.

Formic acid (hcooh) is known to decompose in the presence of a ruthenium-carbon catalyst to produce carbon monoxide, carbon dioxide and hydrogen ${ }^{16}$. Under different conditions, the decomposition products of formic acid are different. When aerobic participation occurs, the dehydration reaction occurs and the products are carbon monoxide and water. In this experiment, the reaction conditions were high temperature with hydrogen afford and $\mathrm{Ru} / \mathrm{C}$ was used as catalyst, and Under the catalytic action of formic acid, the decomposition reaction of formic acid occurs at $220-280{ }^{\circ} \mathrm{C}$ and generate hydrogen and carbon dioxide. Therefore, in the five solvent conditions of this experiment, the reaction using isopropanol and formic acid as the solvent produced more hydrogen and carbon dioxide than others four solvents. The hydrogen content is $55.43 \%$ and the carbon dioxide content is $3.70 \%$.

Methanol and sludge could react under high temperature conditions, and the by-products are methane and carbon oxides, but from the table we can see that the solvent produced the most methane $(0.83 \%)$ and carbon dioxide (CO: $40.27 \%$; $\mathrm{CO}_{2}$ 0.83\%) was not methanol. One reason is that the gas which was used to flush the reactor was hydrogen, and hydrogen is one product of methanol decomposition, so a reaction system with equal amounts of products has not been formed, thereby consuming a part of the oxygen compounds; The second reason is that if there is only methanol in the reactor, methanol will react near the active center of the catalyst. Because a large amount of reaction heat is generated, the temperature of the place where the reaction occurs is too high, causing the actual temperature to be higher than the detected temperature, and these local heat will 
lead to faster deactivation of the catalyst coke, which will destroy the stability of the catalyst.Therefore, if the amount of methanol in the reaction system is generated in turn, the catalytic performance of the catalyst will be reduced first, resulting in an increase in the content of by-products and methane gas. As a result, it has increased.

For the experiments with the ethanol as a part of the solvents, the gas produced was relatively small, and the hydrogen (41.29\%) was only less than the formic acid. The reason is that organic matter may be decomposed to produce hydrogen during the catalytic cracking of sludge. And it is not certain whether the hydrogen is a product or the left hydrogen which was use to flush the reactor.

\section{Conclusion}

Catalysts have a obviously effect on the catalytic hydrogenation of sewage sludge , and catalytic effect of Ir/C, $\mathrm{Pt} / \mathrm{C} 1, \mathrm{Ru} / \mathrm{C}, \mathrm{Pd} / \mathrm{C}$ or $\mathrm{Pt} / \mathrm{C} \mathrm{c}$ are relatively high.

$\mathrm{Pt} / \mathrm{C} 1$ catalyst has a better effect on the catalytic hydropyrolysis of sewage sludge, and the gas phase product using the $\mathrm{Pt} / \mathrm{C} 1$ catalyst contains a large amount of $\mathrm{co}$, which can be used as a reducing agent, such as Industrial reduced iron oxide (prepared iron) $\left(\mathrm{CO}+\mathrm{F}_{e 2} \mathrm{O}_{3}=2 \mathrm{~F}_{e}+3 \mathrm{CO}_{2}\right)$. Methanol is a chemical raw material and can also be used to produce acetic acid. It is often used as an organic extractant and analytical reagent (solvent, chromatographic analysis reagent). It is a better solvent than ethanol, it can dissolve many inorganic salts, and can be blended into gasoline Used as an alternative fuel. Methanol has also become a new fuel for the twenty-first century. It is easily pressurized into a liquid and easy to store. It is a new liquid fuel (alcohol-ether fuel) with a certain proportion of dimethyl ether. It has both combustion efficiency and thermal efficiency. It is higher than liquefied gas. Therefore, it can also be used to produce methanol, which will help improve the resource efficiency of sludge and achieve indirect resource utilization of sludge.

Based on the above conditions, in this experimental study, the sludge catalytic hydrogenation performance is good, and the $\mathrm{Pt} / \mathrm{C} 1$ catalyst is used to produce valuable small molecules with a high yield.

The substances in the solid phase of sludge pyrolysis are mainly inorganic phosphates and fatty alcohols. The gas products after sludge pyrolysis are mostly $\mathrm{CO}, \mathrm{CO}_{2}, \mathrm{CH}_{4}$, and the main components in the sludge pyrolysis liquid phase are some small organic molecules: alcohols, esters, alkanes, olefins, furans, pyrimidines, carboxylic acids, furoic acids, and ketones.

Received: 9 July 2020; Accepted: 19 October 2020

Published online: 03 November 2020

\section{References}

1. Ting, Y., Discussion on municipal sludge treatment and disposal. In Green Environmental Protection Building Materials, Vol. 50 (2017).

2. Yang, W., Zhang Q., Yang Q., \& Zhu Q. A review on municipal sludge dewatering and bioleaching conditioning technologies. In Industrial Water Treatment, Vol. 11 (2018).

3. Zhang, X. Discussion on Municipal Sewage Plant Sludge Disposal Technology. In Guangdong Chemical Industry, Vol. 146 (2018).

4. Tyagi, V. K. \& Lo, S. Sludge: a waste or renewable source for energy and resources recovery?. Renew. Sust. Energ. Rev. 25, 708 (2013).

5. Kui, W., Chemistry at a new level: one of the development trends of chemistry. Jiangsu Ch. Em. Ical. Indust. Ry. 1 (1998).

6. Siliang, Z. Multi Scale Microbial Process Optimization (Chemical Industry Press, Beijing, 2003).

7. Jing, L. Micro/Nano Scale Heat Transfer (Science Press, BeiJing, 2001).

8. Bruchmueller, J., van Wachem, B. G. M., Gu, S., Luo, K. H. \& Brown, R. C. Modeling the thermochemical degradation of biomass inside a fast pyrolysis fluidized bed reactor. AICHE J. 58, 3030 (2012).

9. Qiang, W. Z. Multi Scale Analysis of Composite Materials (Southwest Jiaotong University Press, Chengdu, 2015).

10. Bian, H., Zheng, B., Chen, L. \& Zhu, H. Multi-scale structures and physicochemical properties of highland barley starch following dry heat treatment. J. Food. Sci. 41(7), 93-101 (2020).

11. Feng, M. J., PhD, Beijing Forestry University (2014) (in Chinese).

12. Hervy, M. et al. Multi-scale characterisation of chars mineral species for tar cracking. Fuel 189, 88 (2017).

13. Fini, E. H. et al. Multiscale investigation of a bioresidue as a novel intercalant for sodium montmorillonite. J. Phys. Chem. C 121, 1794 (2017).

14. Pingali, S. V. et al. Understanding multiscale structural changes during dilute acid pretreatment of switchgrass and poplar. ACS Sustain. Chem. Eng. 5, 426 (2017).

15. Chakraborty, S., Raju, S. \& Pal, R. K. A multiscale three-zone reactive mixing model for engineering a scale separation in enzymatic hydrolysis of cellulose. Bioresour. Technol. 173, 140 (2014).

16. Gnyp, M. L. et al. Development and implementation of a multiscale biomass model using hyperspectral vegetation indices for winter wheat in the North China Plain. Int. J. Appl. Earth Obs. 33, 232 (2014).

17. Bello-Perez, L. A., Agama-Acevedo, E., Garcia-Valle, D. E. \& Alvarez-Ramirez, J. A multiscale kinetics model for the analysis of starch amylolysis. Int. J. Biol. Macromol. 122, 405-409 (2019).

18. Sharifzadeh, M. et al. The multi-scale challenges of biomass fast pyrolysis and bio-oil upgrading: review of the state of art and future research directions. Prog. Energy Combust. 71, 1-80 (2019).

19. Guan Yanjun, PhD, North China Electric Power University (Beijing) (2017) (in Chinese).

20. Juhui, C. et al. Analysis of biomass gasification in bubbling fluidized bed with a revised bubble-based energy minimization multiscale drag model. Chem. Ind. Eng. Prog. 36, 1224 (2017).

21. Zhao, L. et al. Enhanced photo bio-reaction by multiscale bubbles. Chem. Eng. J. 354, 304 (2018).

22. Pecha, M. B. et al. Integrated particle- and reactor-scale simulation of pine pyrolysis in a fluidized bed. Energy Fuel 32, 10683 (2018).

23. Ciesielski, P. N. et al. Advancing catalytic fast pyrolysis through integrated multiscale modeling and experimentation: challenges, progress, and perspectives. Wires Energy Environ. 7, e297 (2018).

24. Hosseini, S. A., Lambert, R., Kucherenko, S. \& Shah, N. Multiscale modeling of hydrothermal pretreatment: from hemicellulose hydrolysis to biomass size optimization. Energy Fuel 24, 4673 (2010).

25. Zhang, Y. \& Chen, H. Multiscale modeling of biomass pretreatment for optimization of steam explosion conditions. Chem. Eng. Sci. 75, 177 (2012) 
26. Bodenschatz, C., Zhang, X., Xie, T. \& Getman, R., Molecular-level insights into the role of water on the chemistry of sugar alcohol decompositions revealed by multiscale modeling. In Abstracts of Papers of the American Chemical Society, Vol. 256 (2018).

27. $\mathrm{Bu}$, L. et al., Understanding diffusion during catalytic fast pyrolysis of biomass over H-ZSM-5 by multiscale modeling. In Abstracts of Papers of the American Chemical Society, Vol. 253 (2017).

28. Krumm, C., Paulsen, A. \& Dauenhauer, P., Multiscale experimental determination of cellulose pyrolysis reaction chemistry and transport phenomena. In Abstracts of Papers of the American Chemical Society, Vol. 249 (2015).

29. Pannala, S. et al., Multiscale/multiphysics modeling of biomass fast pyrolysis and vapor phase upgrading reactors. In Abstracts of Papers of the American Chemical Society, Vol. 249 (2015).

30. Bulo, R. E. \& Jiang, T., Multiscale modeling of chemistry in water: applications in biomass conversion. In Abstracts of Papers of the American Chemical Society, Vol. 248 (2014).

31. Catapan, R. C. et al. First-principles-based multiscale modeling of the water-gas shift reaction on platinum and nickel surfaces. Abstracts of Papers of the American Chemical Society 244, 1155 (2012).

32. Mayer-Laigle, C. et al. DRY biorefineries: multiscale modeling studies and innovative processing. Innov. Food Sci. Emerg. 46, 131 (2018).

33. Isaac, A. et al. From nano- to micrometer scale: the role of microwave-assisted acid and alkali pretreatments in the sugarcane biomass structure. Biotechnol. Biofuels 11, 1-11 (2018).

34. Lima, C. S. et al. Multiscale alterations in sugar cane bagasse and straw submitted to alkaline deacetylation. ACS Sustain. Chem. Eng. 6, 3796 (2018).

35. Nishida, M., Tanaka, T., Miki, T., Ito, T. \& Kanayama, K. Multi-scale instrumental analyses for structural changes in steam-treated bamboo using a combination of several solid-state NMR methods. Ind. Crop. Prod. 103, 89 (2017).

36. Martinez-Hernandez, E. Trends in sustainable process design-from molecular to global scales. Curr. Opin. Chem. Eng. 17, 35 (2017).

37. Bates, R. B. et al. Steam-air blown bubbling fluidized bed biomass gasification (BFBBG): multi-scale models and experimental validation. AICHE J. 63, 1543 (2017).

38. Powell, J. B. Application of multiphase reaction engineering and process intensification to the challenges of sustainable future energy and chemicals. Chem. Eng. Sci. 157, 15 (2017).

39. Yung, M. M. et al. Multiscale evaluation of catalytic upgrading of biomass pyrolysis vapors on Ni- and Ga-modified ZSM-5. Energy Fuel 30, 9471 (2016).

40. Colin, J., Remond, R. \& Perre, P. Design and optimization of industrial woody biomass pretreatment addressed by DryKiln_CRP, a multiscale computational model: Particle, bed, and dryer levels. Dry Technol. 34, 1820 (2016).

41. Dudukovic, M. P. \& Mills, P. L. Scale-up and multiphase reaction engineering. Curr. Opin. Chem. Eng. 9, 49 (2015).

42. Inouye, H. et al. Multiscale deconstruction of molecular architecture in corn stover. Sci. Rep-UK 4, 1-7 (2014).

43. Mohan, M., Viswanath, P., Banerjee, T. \& Goud, V. V. Multiscale modelling strategies and experimental insights for the solvation of cellulose and hemicellulose in ionic liquids. Mol. Phys. 116, 2108 (2018).

44. Perrier, L. et al. Plasticity of sorghum stem biomass accumulation in response to water deficit: a multiscale analysis from internode tissue to plant level. Front. Plant Sci. 8, 1516 (2017).

45. Andersson, J., Umeki, K., Furusjo, E., Kirtania, K. \& Weiland, F. Multiscale reactor network simulation of an entrained flow biomass gasifier: model description and validation. Energy Technol-Ger 5, 1484 (2017).

46. Mushrif, S. H., Vasudevan, V., Krishnamurthy, C. B. \& Venkatesh, B. Multiscale molecular modeling can be an effective tool to aid the development of biomass conversion technology: a perspective. Chem. Eng. Sci. 121, 217 (2015).

47. Yue, D., You, F. \& Snyder, S. W. Biomass-to-bioenergy and biofuel supply chain optimization: overview, key issues and challenges. Comput. Chem. Eng. 66, 36 (2014).

48. Andersen, F. E., Diaz, M. S. \& Grossmann, I. E. Multiscale strategic planning model for the design of integrated ethanol and gasoline supply chain. AICHE J. 59, 4655 (2013).

49. Jin, G. Multiscale coupling framework for modeling of large-size biomass particle gasification in fluidized beds. Ind. Eng. Chem. Res. 52, 11344 (2013).

50. Yu-Wu, Q.M., Weiss-Hortala, E. \& Barna, R., Hydrothermal conversion of glucose in multiscale batch processes. Analysis of the gas, liquid and solid residues. J. Supercrit. Fluid 7976 (2013).

51. Iliuta, I. \& Larachi, F. Dynamics of fines/bacterial cells accumulation in trickle-bed reactors/bioreactors-multiscale modeling framework. Comput. Math. Appl. 65, 1698 (2013).

52. Hunt, K. A., Jennings, R. M., Inskeep, W. P. \& Carlson, R. P. Multiscale analysis of autotroph-heterotroph interactions in a hightemperature microbial community. PLoS Comput. Biol. 14, e1006431 (2018).

53. Chew, Y. H. et al. Multiscale digital Arabidopsis predicts individual organ and whole-organism growth. Proc. Natl. Acad. Sci. USA 111, E4127 (2014).

54. Vlachos, D., Recent advances in multiscale modeling for biomass conversion. In Abstracts of Papers of the American Chemical Society, Vol. 243 (2012).

55. Vlachos, D. High throughput multiscale modeling: informatics strategies for experimental assessment, catalyst screening, model reduction, and uncertainty analysis. Abstracts of Papers of the American Chemical Society 243, 1155 (2012).

56. Caratzoulas, S. et al. Multiscale modeling in the catalysis center for energy innovation for biomass conversion to fuels and chemicals. Abstracts of Papers of the American Chemical Society 241, 1155 (2011).

57. Perre, P. Multiscale modeling of drying as a powerful extension of the macroscopic approach: application to solid wood and biomass processing. Dry Technol. 28, 944 (2010).

58. Hosseini, S. A., Lambert, R., Kucherenko, S. \& Shah, N. Multiscale modeling of hydrothermal pretreatment: from hemicellulose hydrolysis to biomass size optimization. Energy Fuel 24, 4673 (2010).

59. Hosseini, S. A. \& Shah, N. Multiscale modelling of biomass pretreatment for biofuels production. Chem. Eng. Res. Des. 87, 1251 (2009).

60. He, C., Zhao, J., Yang, Y. \& Wang, J. Multiscale characteristics dynamics of hydrochar from hydrothermal conversion of sewage sludge under sub- and near-critical water. Bioresour. Technol. 211, 486 (2016).

61. Zhang, J. et al. Multiscale visualization of the structural and characteristic changes of sewage sludge biochar oriented towards potential agronomic and environmental implication. Sci. Rep-UK 5, 1-8 (2015).

62. Sun, G. M. Multi Scale Effect in the Process of Material Transformation (Heilongjiang Education Press, Harbin, 2002).

63. Syed-Hassan, S. S. A., Wang, Y., Hu, S., Su, S. \& Xiang, J. Thermochemical processing of sewage sludge to energy and fuel: fundamentals, challenges and considerations. Renew. Sustain. Energy Rev. 80, 888 (2017).

64. Alvarez, J. et al. Sewage sludge valorization by flash pyrolysis in a conical spouted bed reactor. Chem. Eng. J. 273, 173 (2015).

65. Werpy, T. \& Petersen, G. (2004).

66. Biddy, M. J., Scarlata, C. \& Kinchin, C. (2016).

67. Li, Y. et al. Activated carbon preparation from pyrolysis char of sewage sludge and its adsorption performance for organic compounds in sewage. Fuel 266, 117053 (2020).

68. Fan, J. et al. Using sewage sludge with high ash content for biochar production and $\mathrm{Cu}(\mathrm{II})$ sorption. Sci. Total Environ. 713, 136663 (2020). 
69. Peng, G. et al. Synthesis of $\mathrm{Mn} / \mathrm{Al}$ double oxygen biochar from dewatered sludge for enhancing phosphate removal. J. Clean. Prod. 251, 119725 (2020).

70. Taki, K., Choudhary, S., Gupta, S. \& Kumar, M. Enhancement of geotechnical properties of municipal sewage sludge for sustainable utilization as engineering construction material. J. Clean. Prod. 251, 119723 (2020).

71. Chu, Q. et al. Sewage sludge-derived hydrochar that inhibits ammonia volatilization, improves soil nitrogen retention and rice nitrogen utilization. Chemosphere 245, 125558 (2020).

72. Huang, T., Ding, T., Liu, D. \& Li, J. Degradation of carbendazim in soil: effect of sewage sludge derived biochars. J. Agric. Food Chem. 68(12), 3703-3710 (2020).

73. Das, P. et al. Energy recovery and nutrients recycling from municipal sewage sludge. Sci. Total Environ. 715, 136775 (2020).

74. Wei, W. et al. How does synthetic musks affect methane production from the anaerobic digestion of waste activated sludge?. Sci. Total Environ. 713, 136594 (2020).

75. Lu, D. et al. Liquid and solids separation for target resource recovery from thermal hydrolyzed sludge. Water Res. 171, 115476 (2020).

76. Xiao, K. \& Zhou, Y. Protein recovery from sludge: a review. J. Clean. Prod. 249, 119373 (2020).

77. Madrid, F., Rubio-Bellido, M. \& Morillo, E. Extraction of nonylphenol, pyrene and phenanthrene from sewage sludge and composted biosolids by cyclodextrins and rhamnolipids. Sci. Total Environ. 715, 136986 (2020).

78. Ma, J. et al. Evaluation of the fate of nutrients, antibiotics, and antibiotic resistance genes in sludge treatment wetlands. Sci. Total Environ. 712, $136370(2020)$

79. Pang, H. et al. Cation exchange resin-induced hydrolysis for improving biodegradability of waste activated sludge: characterization of dissolved organic matters and microbial community. Bioresour. Technol. 302, 122870 (2020).

80. Liu, X. et al. Municipal sludge dewatering properties and heavy metal distribution: effects of surfactant and hydrothermal treatment. Sci. Total Environ. 710, 136346 (2020).

81. Kou, Y. et al. Removal of heavy metals in sludge via joint EDTA-acid treatment: effects on seed germination. Sci. Total Environ. 707, $135866(2020)$.

82. Xiang, T., Gao, D. \& Wang, X. Performance and microbial community analysis of two sludge type reactors in achieving mainstream deammonification with hydrazine addition. Sci. Total Environ. 715, 136377 (2020).

83. Qin, R. et al. Effects of exposure to polyether sulfone microplastic on the nitrifying process and microbial community structure in aerobic granular sludge. Bioresour. Technol. 302, 122827 (2020).

84. Koyama, M. et al. Ammonia recovery and microbial community succession during thermophilic composting of shrimp pond sludge at different sludge properties. J. Clean. Prod. 251, 119718 (2020).

85. Gong, Z. et al. Catalytic pyrolysis of chemical extraction residue from microalgae biomass. Renew. Energy 148, 712 (2020).

86. Hu, Q., Dai, Y. \& Wang, C. Steam co-gasification of horticultural waste and sewage sludge: Product distribution, synergistic analysis and optimization. Bioresour. Technol. 301, 122780 (2020).

87. Wang, T. et al. Co-pyrolysis behavior of sewage sludge and rice husk by TG-MS and residue analysis. J. Clean. Prod. 250, 119557 (2020).

88. Zhuang, X. et al., Pyrolytic conversion of biowaste-derived hydrochar: decomposition mechanism of specific components. Fuel $266(2020)$.

89. Toutian, V., Barjenbruch, M., Unger, T., Loderer, C. \& Remy, C. Effect of temperature on biogas yield increase and formation of refractory COD during thermal hydrolysis of waste activated sludge. Water Res. 171, 115383 (2020).

90. Shahbeig, H. \& Nosrati, M. Pyrolysis of municipal sewage sludge for bioenergy production: Thermo-kinetic studies, evolved gas analysis, and techno-socio-economic assessment. Renew. Sustain. Energy Rev. 119, 109567 (2020).

91. Ahn, H., Kim, D. \& Lee, Y. Combustion characteristics of sewage sludge solid fuels produced by drying and hydrothermal carbonization in a fluidized bed. Renew. Energy 147, 957 (2020).

92. Moretto, G. et al. An urban biorefinery for food waste and biological sludge conversion into polyhydroxyalkanoates and biogas. Water Res. 170, 115371 (2020).

93. Zhang, Q. et al. Enhanced volatile fatty acids production from waste activated sludge with synchronous phosphorus fixation and pathogens inactivation by calcium hypochlorite stimulation. Sci. Total Environ. 712, 136500 (2020).

94. Ripoll, V., Agabo-Garcia, C., Perez, M. \& Solera, R. Improvement of biomethane potential of sewage sludge anaerobic co-digestion by addition of "sherry-wine" distillery wastewater. J. Clean. Prod. 251, 119667 (2020).

95. Zhao, Z., Sun, C., Li, Y., Peng, H. \& Zhang, Y. Upgrading current method of anaerobic co-digestion of waste activated sludge for high-efficiency methanogenesis: Establishing direct interspecies electron transfer via ethanol-type fermentation. Renew. Energy $148,523(2020)$

96. Ye, M. et al. In-situ ammonia stripping with alkaline fermentation of waste activated sludge to improve short-chain fatty acids production and carbon source availability. Bioresour. Technol. 301, 122782 (2020).

97. Fan, C. et al. Triclosan enhances short-chain fatty acid production from sludge fermentation by elevating transcriptional activity of acidogenesis bacteria. Chem. Eng. J. 384, 123285 (2020).

98. Wang, Y., Agarwal, S., Tang, Z. \& Heeres, H. J. Exploratory catalyst screening studies on the liquefaction of model humins from C6 sugars. RSC Adv. 7, 5136 (2017).

99. 张家栋, 硕士, 哈尔滨工业大学 (2016) (in Chinese)

100. 王兴润, 金宜英, 王志玉, 杜欣 \& 聂永丰, 应用TGA-FTIR研究不同来源污泥的燃烧和热解特性. 燃料化学学报 27 (2007) (in Chinese).

101. 陈绍伟,赵由于,徐迪民, 污泥的DSC和TGA分析. 环境工程 38 (1994) (in Chinese)

102. 王兴润, 金宜英, 王志玉, 杜欣 \& 聂永丰, 应用TGA-FTIR硎究不同来源污泥的燃烧和热解特性. 燃料化学学报 27 (2007) (in Chinese).

103. 李素玉, 环境微生物分类与检测技术 (2005) (in Chinese).

\section{Acknowledgements}

The authors acknowledge Yang Cao (Guizhou University) and Feng Xie (Guizhou Academy of Testing and Analysis) for analytical support and Jiang Li and Jian Zhu, Xingqiang Guo and Yonggui Wu (Guizhou University) for technical support.

\section{Author contributions}

All author took part in the experiments, and all authors reviewed the manuscript.

\section{Funding}

This research was performed within the framework of the Young talent introduction program of GZU, No. (2018)25. The authors gratefully acknowledge the support of the Guizhou University. 


\section{Competing interests}

The authors declare no competing interests.

\section{Additional information}

Supplementary information is available for this paper at https://doi.org/10.1038/s41598-020-75980-Z.

Correspondence and requests for materials should be addressed to Y.W.

Reprints and permissions information is available at www.nature.com/reprints.

Publisher's note Springer Nature remains neutral with regard to jurisdictional claims in published maps and institutional affiliations.

(c) (i) Open Access This article is licensed under a Creative Commons Attribution 4.0 International cc) License, which permits use, sharing, adaptation, distribution and reproduction in any medium or format, as long as you give appropriate credit to the original author(s) and the source, provide a link to the Creative Commons licence, and indicate if changes were made. The images or other third party material in this article are included in the article's Creative Commons licence, unless indicated otherwise in a credit line to the material. If material is not included in the article's Creative Commons licence and your intended use is not permitted by statutory regulation or exceeds the permitted use, you will need to obtain permission directly from the copyright holder. To view a copy of this licence, visit http://creativecommons.org/licenses/by/4.0/.

(C) The Author(s) 2020 